\title{
New constraints on the 1922 Atacama, Chile, earthquake from Historical seismograms
}

\author{
Hiroo Kanamori, ${ }^{1}$ Luis Rivera, ${ }^{2}$ Lingling Ye, ${ }^{3}$ Thorne Lay, ${ }^{4}$ Satoko Murotani ${ }^{5}$ and \\ Kenshiro Tsumura ${ }^{6}$ \\ ${ }^{1}$ Seismological Laboratory, California Institute of Technology, Pasadena, CA 91125, USA.E-mail: hiroo@gps.caltech.edu \\ ${ }^{2}$ Institut de Physique du Globe de Strasbourg; UMR7516, University of Strasbourg-CNRS, Strasbourg, France \\ ${ }^{3}$ Guangdong Provincial Key Laboratory of Geodynamics and Geohazards, School of Earth Sciences and Engineering, Sun-Yat Sen University, Guanzhou \\ 510275, China \\ ${ }^{4}$ Department of Earth and Planetary Sciences, University of California Santa Cruz, Santa Cruz, CA 95064, USA \\ ${ }^{5}$ Department of Science and Engineering, National Museum of Nature and Science, Tsukuba, Japan \\ ${ }^{6}$ Association for the Development of Earthquake Prediction, Tokyo, Japan
}

Accepted 2019 July 2. Received 2019 June 28; in original form 2019 February 20

\begin{abstract}
SUMMAR Y
We recently found the original Omori seismograms recorded at Hongo, Tokyo, of the 1922 Atacama, Chile, earthquake $\left(M_{S}=8.3\right)$ in the historical seismogram archive of the Earthquake Research Institute (ERI) of the University of Tokyo. These recordings enable a quantitative investigation of long-period seismic radiation from the 1922 earthquake. We document and provide interpretation of these seismograms together with a few other seismograms from Mizusawa, Japan, Uppsala, Sweden, Strasbourg, France, Zi-ka-wei, China and De Bilt, Netherlands. The 1922 event is of significant historical interest concerning the cause of tsunami, discovery of $G$ wave, and study of various seismic phase and first-motion data. Also, because of its spatial proximity to the 1943, 1995 and 2015 great earthquakes in Chile, the 1922 event provides useful information on similarity and variability of great earthquakes on a subduction-zone boundary. The 1922 source region, having previously ruptured in 1796 and 1819 , is considered to have significant seismic hazard. The focus of this paper is to document the 1922 seismograms so that they can be used for further seismological studies on global subduction zones. Since the instrument constants of the Omori seismographs were only incompletely documented, we estimate them using the waveforms of the observed records, a calibration pulse recorded on the seismogram and the waveforms of better calibrated Uppsala Wiechert seismograms. Comparison of the Hongo Omori seismograms with those of the 1995 Antofagasta, Chile, earthquake $\left(M_{\mathrm{w}}=8.0\right)$ and the 2015 Illapel, Chile, earthquake $\left(M_{\mathrm{w}}=8.3\right)$ suggests that the 1922 event is similar to the 1995 and 2015 events in mechanism (i.e. on the plate boundary megathrust) and rupture characteristics (i.e. not a tsunami earthquake) with $M_{\mathrm{w}}=8.6 \pm 0.25$. However, the initial fine scale rupture process varies significantly from event to event. The G1 and G2, and R1 and R2 of the 1922 event are comparable in amplitude, suggesting a bilateral rupture, which is uncommon for large megathrust earthquakes.
\end{abstract}

Key words: Earthquake dynamics; Earthquake source observation; Surface waves and free oscillations; Dynamics and mechanics of faulting; Subduction zone processes.

\section{INTRODUCTION}

The 11 November 1922 Atacama, Chile, earthquake $[M=8.3$ (Gutenberg \& Richter 1954), $M_{S}=8.3$ (Abe 1981), $M_{\mathrm{w}}=8.3 \pm 0.4$ (ISC-GEM catalogue, Storchak et al. 2015); $-28.911^{\circ},-70.87^{\circ}$, depth $35 \mathrm{~km}$ (ISC-GEM)] is the second largest earthquake in Chile in the 20th century, next to the $M_{\mathrm{w}}=9.51960$ Valdivia, Chile, earthquake (Davison 1929; Willis 1929; Lomnitz 1970; Beck et al.
1998; Carvajal et al. 2017a; Ruiz \& Madariaga 2018). It caused extensive shaking and tsunami damage extending from Chañaral $\left(26^{\circ} \mathrm{S}\right)$ to Coquimbo $\left(30^{\circ} \mathrm{S}\right)$, and tsunami damage occurred in Japan (Willis 1929; Soloviev \& Go 1975). GPS measurements indicate that the plate boundary is accumulating slip deficit along the entire 1922 source region and there is potential for future large earthquakes in this region (e.g. Nishenko 1985; Métois et al. 2016, Fig. 1). The 1922 earthquake is also a unique event in the history of 


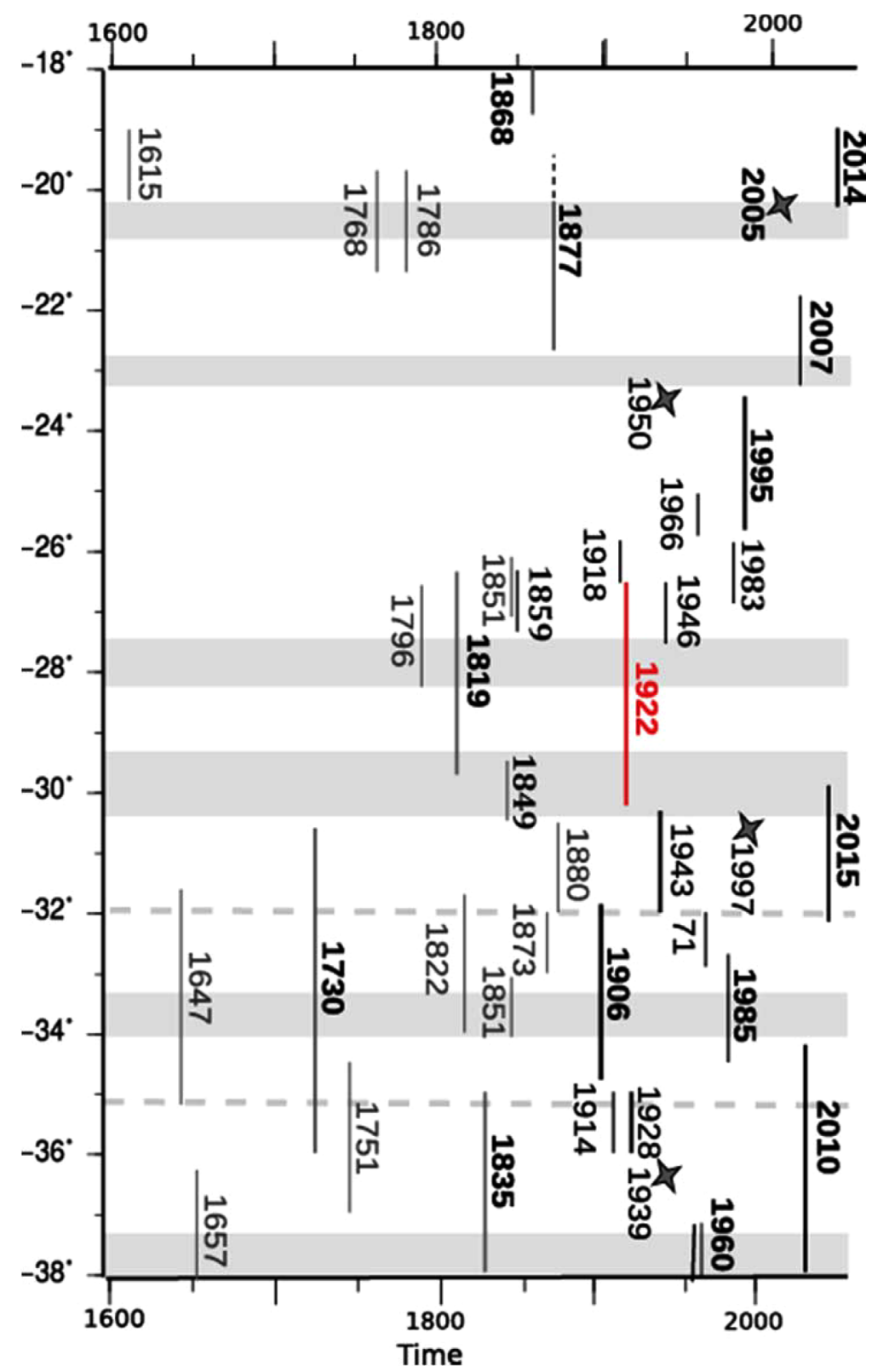

Figure 1. Timeline of large earthquakes along the Chilean coast. (Modified from fig. 2 of Métois et al. 2016.) Stars represent intraplate events, and lines represent interplate rupture extent. Grey bars are areas of inferred low coupling from geodesy.

seismology in several respects: (1) Historical debates about the origin of tsunami (faulting versus landslide) were made with this earthquake (Gutenberg 1939). (2) Gutenberg (1924) (also Sieberg \& Gutenberg 1924) studied many seismograms of this earthquake in great detail and noted distinct long-period horizontal component surface waves with a propagation speed of about $4.4 \mathrm{~km} \mathrm{~s}^{-1}$ that were later named $G$ waves (Byerly 1926; Richter 1958). $G$ waves played an important role in the early determination of the upper mantle structure and low-velocity layer (e.g. Satô 1958; Press 1959). (3) By the time the 1922 event occurred, the basic structure of the earth's interior had been established (e.g. Oldham 1906; Gutenberg 1914), and the many seismic phases Gutenberg (1924) identified on the seismograms of the 1922 event provided the basis for further significant refinement. (4) The $P$ wave first motion data from the 1922 event demonstrated that the first motions had both compression and dilatation (Byerly 1928). According to Agnew (2002),
Shida showed in 1917 (unpublished) a pattern of first motion divided into quadrants. Shida's paper was published in Shida (1929). Thus, Byerly's observation appeared to have confirmed Shida's result and also predated the widely known single-couple versus double-couple debates (Byerly 1960). A detailed account of the history of studies on the initial motion of an earthquake can be found in Kawasumi (1937). (5) The recent 2015 Illapel, Chile, earthquake $\left(M_{\mathrm{w}}=8.3\right)$, the 1943 Illapel earthquake $\left(M_{S}=7.9\right.$, Abe 1981) and the 1995 Antofagasta earthquake $\left(M_{\mathrm{w}}=8.1\right)$ occurred adjacent to the 1922 rupture zone (Fig. 1) and these events together provide important information on similarity and variability of subduction-zone great earthquake sequences.

However, despite the large magnitude of the 1922 event, relatively few seismograms have been available for quantitative investigation since Gutenberg (1924). Beck et al. (1998), investigated 
the $P$ wave recorded on the De Bilt Galitzin seismogram and concluded that the 1922 event was a megathrust event much larger and more complex than the 1943 Illapel earthquake. Okal (1992) briefly reported the results of spectral measurements from Uppsala seismograms, and gave a mantle-wave magnitude of $M_{m}=8.56-8.61$, and noted that this value is more or less consistent with the size of this event estimated from the aftershock area (Kanamori 1977) and the tsunami (Abe 1979). Recently, we found the original Omori seismograms of the 1922 earthquake in the historical seismogram archive of the Earthquake Research Institute (ERI) of the University of Tokyo. This record allows us to make a quantitative investigation of long-period seismic radiation from the 1922 earthquake. Here we document this observation and interpret it in light of modern seismological practice.

\section{OMORI SEISMOGRAMS RECORDED AT HONGO, TOK YO, JAPAN}

The seismograms used here actually were published in Matuzawa (1929, p. 215), Imamura (1937, p. 293) and Satô (1978, p. 283), but the instrument response parameters of these records were not given in these publications. Fortunately, we could find the original Omori long-period smoked paper seismograms recorded at Hongo, Tokyo, Japan $\left(35.717^{\circ}, 139.767^{\circ}\right)$ along with some instrumental details in the ERI historical seismogram archive.

Fig. 2(a) shows the seismograms of the 1922 earthquake, probably hand-traced from the original Omori seismograms, and published in Matuzawa (1929). It clearly shows long-period Love (G1 and G2) and Rayleigh (R1 and R2) waves. For historical interest, we quote a few sentences from Matuzawa (1929) and Imamura (1937). 'From the theoretical point of view, Rayleigh wave can be propagated along a surface of a certain medium. In addition to this, waves of Love's type can also be propagated if the medium is stratified under the boundary surface. Whether or no such waves are really existent is a problem which can easily be solved by seismometry. And yet some physicists are often skeptical of the real existence of surface waves, perhaps from difficulty of accurate identification of waves. On the other hand, even among seismologists, there is a diversity of opinion on the separate existence of two kinds of surface waves, that is the Love's type and Rayleigh's type owing to the lack of typical examples free from ambiguity. Therefore, some typical seismograms will be reproduced here.' (Matuzawa 1929). 'In teleseismic observations these waves (surface waves) appear after the $S$ waves. The first kind, especially, owing to their long-period, are called $L$ waves. The second kind, owing to their amplitude being maximum, are called $M$ waves ... That these phases are surface waves is evident from the fact that the timedistance curves are straight lines; and that the $L$ is a Love wave and $M$ a Rayleigh wave is, as pointed out by Matuzawa, strongly suggested by the azimuth of their vibrations and other features.' (Imamura 1937). It is remarkable that the nature of long-period Love (G) and Rayleigh waves had been already very accurately described in these publications in the early days of seismology. Figs 2(b) and (c) show the G1 and Rayleigh (R1) waves, respectively, recorded on the original Omori smoked-paper seismogram.

The nominal instrument constants of the Omori seismographs that recorded these waves are listed in the data sheets archived at ERI as follows.

NS component: Period $T_{s}=60 \mathrm{~s}$, Gain (Static Magnification) $V=20$, paper speed $2.8 \mathrm{~cm} \mathrm{~min}^{-1}$.
EW component: Period $T_{s}=60 \mathrm{~s}$, Gain (Static Magnification) $V=15$, paper speed $2.8 \mathrm{~cm} \mathrm{~min}^{-1}$.

It is most instructive to compare the 1922 Omori seismograms with the seismograms of the 1995 Antofagasta, Chile, earthquake (GCMT: $-24.17^{\circ},-70.74^{\circ}$, depth $28.7 \mathrm{~km}, M_{\mathrm{w}}=8.0$ ) and the 2015 Illapel, Chile, earthquake (GCMT: $-21.13^{\circ},-72.09^{\circ}$, depth $=17.4 \mathrm{~km}, M_{\mathrm{w}}=8.3$ ) recorded at stations close to Hongo, Tokyo. The 1995 Antofagasta earthquake (e.g. Ruegg et al. 1996; Delouis et al. 1997; Carlo et al. 1999; Pritchard et al. 2002; Ye et al. 2016) and the 2015 Illapel earthquake (e.g. Heidarzadeh et al. 2016; Li et al. 2016, 2018; Melgar et al. 2016; An et al. 2017; Ye et al. 2017; Liu et al. 2018) are both typical thrust earthquakes and located just to the north and south of the rupture zone of the 1922 earthquake, respectively (Fig. 1). Fig. 3 compares the 1922 seismograms with those of the 2015 Illapel earthquake observed at F-net station Tsukuba (TSK, 36.214, $140.090^{\circ}$ ) and the 1995 Antofagasta earthquake observed at F-net station Tateyama (TYM, $34.975^{\circ}, 139.845^{\circ}$ ). The record at TSK is not available for the 1995 event. F-net is a broadband seismographic network operated by the National Research Institute for Earth Science and Disaster Resilience (NIED, Japan). The distance $\Delta$, azimuth $\phi$ and back azimuth $\phi_{B}$ are listed in Table 1. We remove the instrument response from the 1995 and 2015 observed seismograms to obtain displacement records and convolve them with the Omori seismograph response (Pendulum period $T_{s}=40 \mathrm{~s}$, damping constant $h=0.6$, and the static magnification $V=20$ for the NS component, and $T_{s}=40 \mathrm{~s}$, $h=0.6$ and $V=15$ for the EW component). We call these seismograms simulated Omori seismograms. In the next section, we will discuss the particular choice of the pendulum period and damping constant used for Fig. 3.

The first long-period pulse at about $2700 \mathrm{~s}$ on the EW component is probably the SS phase. Unfortunately, this pulse on the 1922 seismogram is at the edge of the original smoked paper record, and the period is not reliable. On Fig. 3, the 1995 seismogram, especially the EW component, is strikingly different from either the 1922 or the 2015 seismogram. The 1995 seismogram exhibits strong high frequency coda in the $P$-wave group and surface wave train. For this event, Ihmle \& Madariaga (1996) noticed strong monochromatic coda waves just after the main $P$-wave arrival, and interpreted them as a result of vertically travelling compressional waves in the ocean near the trench. Other investigators (e.g. Wiens 1989; Okamoto 1993 ) found similar waves for other events and interpreted them as multiply reflected compressional waves in the ocean. An intuitive interpretation is that the events with strong coda have relatively large slip up-dip at shallow depths below the seafloor near the trench, thereby generating larger tsunami than deeper events with similar magnitude. The seismograms of the 1922 and 2015 events are similar without particularly strong coda over this frequency band. Thus, even if these three events occurred on the adjacent segments of the plate boundary, they display significant differences in slip behavior at shallow depths. This variability may even occur between events in the same segment.

Aside from the short-period coda, the seismograms of the 1995 and the 2015 events are similar, except for the G2 wavetrain, which is almost missing for the 2015 event but is very large on the 1995 seismogram. This could be due to differences in directivity caused by the northward rupture propagation of the 2015 event (e.g. Heidarzadeh et al. 2016; Li et al. 2016; Tilmann et al. 2016) and the southward rupture propagation of the 1995 event (e.g. Delouis et al. 1997). However, since the azimuth of TSK and TYM from the strike of these events is $54.8^{\circ}$ to $78.2^{\circ}$ (see Table 1 ), the directivity effect 


\section{Atacama, Chile earthquake}

\section{Hongo Omori seismogram $E W T_{0}=60 s, V=15 \quad N S T_{0}=60 s, V=20$}

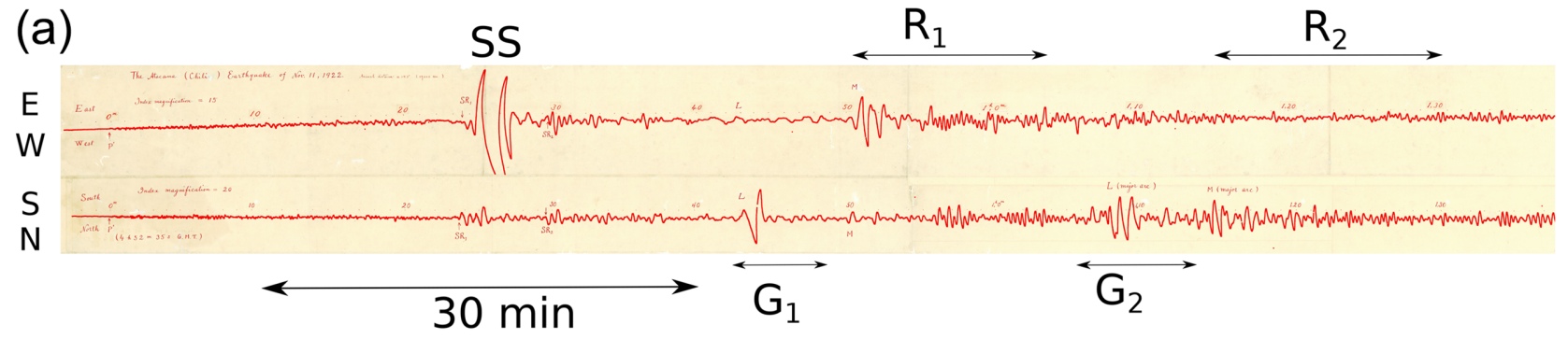

(b)

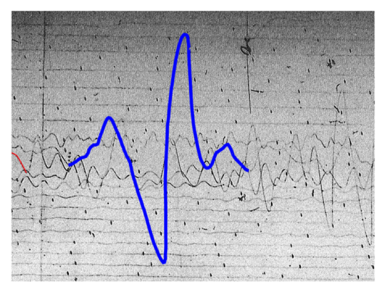

(c)

\section{G1 SN}

P-P: $8.7 \mathrm{~cm}$

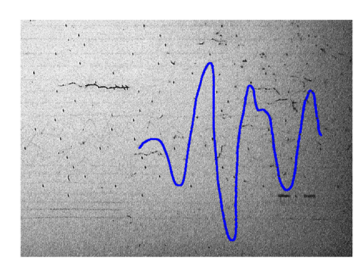

Figure 2. Omori seismograms of the 1922, Atacama, Chile, earthquake recorded at Hongo, Tokyo. (a) Hand-traced seismograms (Matuzawa 1929). The phases $\mathrm{SS}, \mathrm{G} 1, \mathrm{G} 2, \mathrm{R} 1$ and R2 are indicated. The horizontal arrows attached to the phase names indicate the range of group arrival times corresponding to $G$ waves $\left(4.2-4.6 \mathrm{~km} \mathrm{~s}^{-1}\right)$ and Rayleigh waves (3.5-4.1 $\mathrm{km} \mathrm{s}^{-1}$ ). (b) G1 phase and (c) R1 phase recorded on the original smoked paper record, respectively.
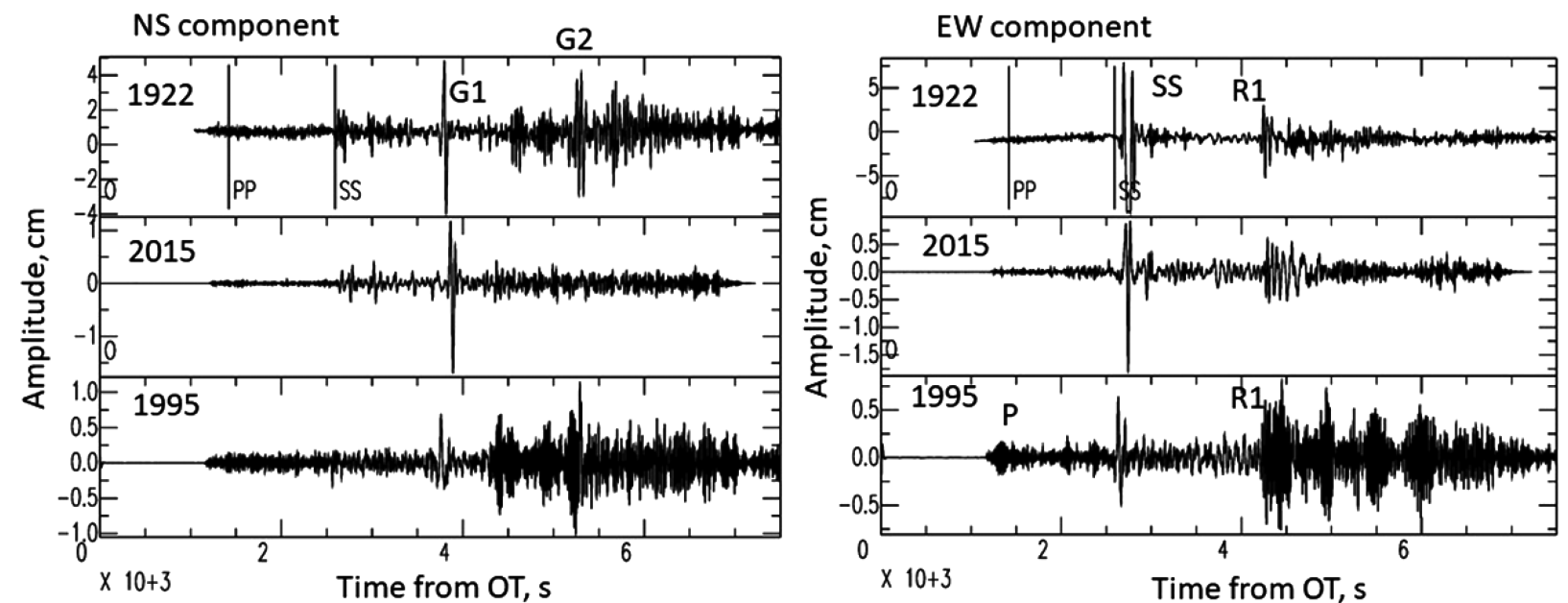

Figure 3. Comparison of the Hongo Omori seismogram of the 1922 Atacama, Chile, earthquake (top) with the simulated Omori seismograms computed from the displacement record of the 2015 Illapel, Chile, earthquake at TSK (middle, $M_{\mathrm{W}}=8.3$ ), and the 1995 Antofagasta, Chile, earthquake at TYM (bottom, $\left.M_{\mathrm{W}}=8.0\right)$. Left-hand panel: NS component $\left(T_{s}=40 \mathrm{~s}, h=0.6, V=20\right)$. Right-hand panel: EW component $\left(T_{s}=40 \mathrm{~s}, h=0.6, V=15\right)$.

Table 1. Event-station data. epicentre (latitude, longitude), station (latitute, longitude), distance, azimuth and backazimuth.

\begin{tabular}{lcccccccc}
\hline Event-station & Lat_e $\left(^{\circ}\right)$ & Long_e $\left(^{\circ}\right)$ & Lat_s $\left({ }^{\circ}\right)$ & Long_s $\left({ }^{\circ}\right)$ & $\Delta\left(^{\circ}\right)$ & $\phi\left(^{\circ}\right)$ & $\phi_{B}\left({ }^{\circ}\right)$ & Strike $\left(^{\circ}\right)$ - $\phi\left(^{\circ}\right)$ \\
\hline 1922-Hongo & -28.91 & -70.87 & 35.717 & 139.767 & 153.3 & 292.6 & 84.0 & - \\
1995-TYM & -24.17 & -70.74 & 34.975 & 139.845 & 151.4 & 299.2 & 76.2 & 54.8 \\
2015-TSK & -31.13 & -72.09 & 36.214 & 140.090 & 152.82 & 288.81 & 87.87 \\
\hline
\end{tabular}

may not be very large, and this amplitude disparity can be partly due to the complex propagation effects (focusing, scattering and attenuation) along the path from Chile to Japan. The 1922 event has intermediate amplitude ratio of G2 to G1 relative to the 2015 and 1995 events.
To facilitate further comparison between the 1922, 2015 and 1995 events, we band-pass filter the records shown in Fig. 3 with a passband of 0.002-0.01 Hz, and the results are shown in Fig. 4(a). In this low-frequency passband, the 1922 waveforms are a factor of 2.5-5 larger than the 2015 and 1995 signals, respectively, with the 2015 event being about twice as large as the 1995 event. The 
(a)

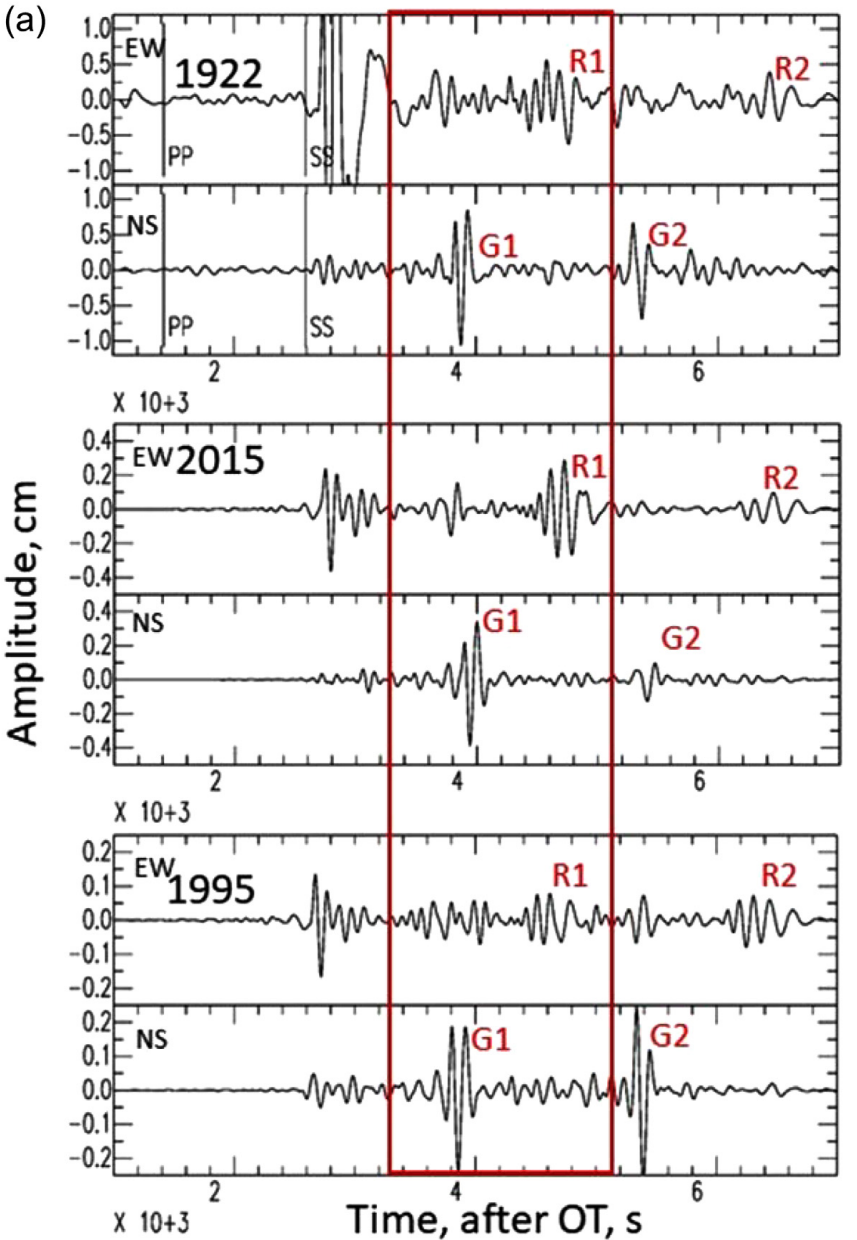

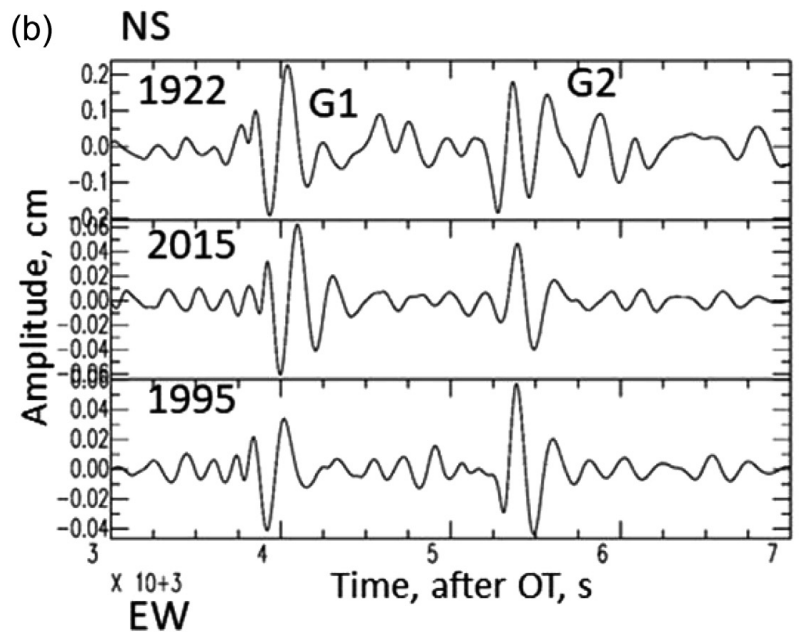

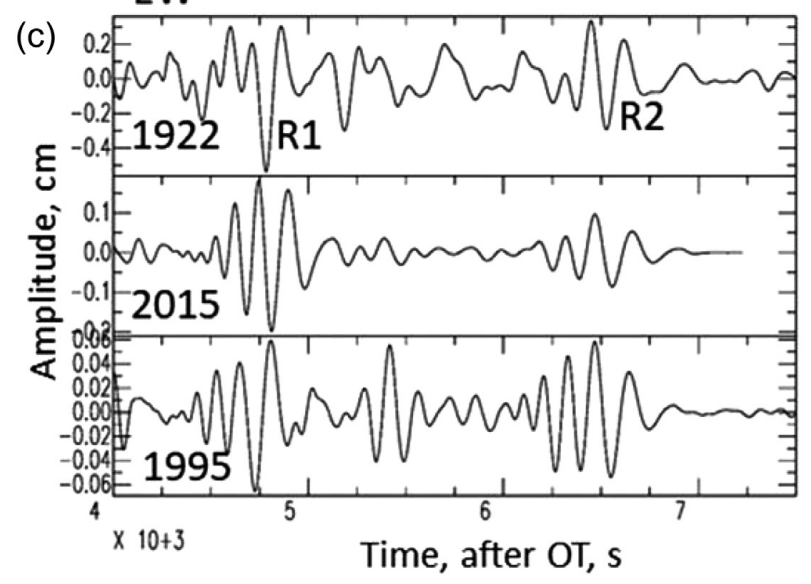

Figure 4. Comparison of the Hongo Omori seismograms of the 1922, 2015 and 1995 Chile earthquakes. (a) Bandpass (0.002-0.01 Hz) filtered records of the seismograms shown in Fig. 3. (b) Bandpass $(0.001-0.005 \mathrm{~Hz})$ filtered records of the NS component seismograms. (c) Bandpass $(0.002-0.008 \mathrm{~Hz})$ filtered records of the EW component seismograms.

peak-to-peak amplitudes of G1, G2, R1 and R2 are summarized in Table 2. Although the ratio G1/R1 varies considerably among the three events, the difference between the 1922 and the 2015 is smaller than that between the 1995 and 2015 megathrust events (see the red box in Fig. 4a). Given the possible variation of the path effects and the limited quality of the Omori seismograms, the overall similarity of the waveforms suggests that the 1922 event is a similar megathrust event, as suggested by Ruiz \& Madariaga (2018).

Compared with Fig. 3, Fig. 4(a) shows G2 and R2 more clearly on the 1922, 2015 and 1995 seismograms. The geometrical focusing and scattering effects are diminished on the longer period passband, and the differences in G2/G1 and R2/R1 amplitude ratios between the three events are probably mainly controlled by the difference in rupture directivity. Fig. 4(b) shows the NS component seismograms at an even lower frequency band, 0.001-0.005 Hz. At this lowfrequency band, the directivity effect almost disappears, yet we can still see the difference between the 1995 and 2015 events. Then, the comparable amplitude of G1 and G2 for the 1922 event despite the longer rupture length suggests that the 1922 event was most likely a bilateral rupture. A similar observation can be made for R1 and R2, as shown in Fig. 4(c). The R2/R1 amplitude ratio of the 1922 event is intermediate of the 2015 and the 1995 events. This is consistent with the location of the epicentre (e.g. $-28.5^{\circ},-70.0^{\circ}$ (Gutenberg \& Richter 1954); $-28.911^{\circ},-70.87^{\circ}$ (ISC-GEM catalogue, Storchak et al. 2015)) relative to the estimated rupture extent (Fig. 1). A bilateral rupture is uncommon for large megathrust events.

If our calibration of the Omori instruments is correct (see the next section), the amplitudes of G1 and R1 shown in Fig. 4(a) and Table 2 indicate that the 1922 event is significantly larger than the 2015 or 1995 event. If we assume that the source durations of these events are approximately the same, we can estimate the $M_{\mathrm{w}}$ of the 1922 event as listed in Table 3 from the amplitude ratios of G1, R1, G2 and R2 between the different events shown in Table 2. If we use the amplitude ratios of $\mathrm{G} 1$, which we believe are the most reliable, the amplitude ratio of 3.0 for the 1922 to the 2015 event translates to a magnitude difference of 0.32 , and the amplitude ratio of 8.5 for the 1922 to the 1995 event, to a magnitude difference of 0.62 . This suggests an $M_{\mathrm{w}}=8.62$ for the 1922 event. The estimate of $M_{\mathrm{w}}$ from G1, R1, G2 and R2 phases ranges from 8.29 to 8.84 (Table 3). Although the Hongo Omori seismograms are the best long-period records we have found so far for the 1922 earthquake, these estimates are from a single station with some assumptions on the instrument constants, and considerable uncertainty is inevitable. For example, since the gain of a mechanical seismograph is approximately proportional to $V T_{s}^{2}$ at periods longer than the pendulum 
Table 2. Peak-to-peak amplitude of SS, G1, R1 and R2 (in cm) on the Hongo, TSK and TYM seismograms.

\begin{tabular}{llccccc}
\hline Event & $\mathrm{SS}^{1}$ & $\mathrm{G} 1^{1}$ & $\mathrm{G}^{2}$ & $\mathrm{R} 1^{2}$ & $\mathrm{G}^{2}$ & $\mathrm{R}^{2}$ \\
\hline $1922\left(M_{S}=8.3\right)$ & 17.0 & $8.71(3.0,8.5)^{3}$ & $1.90(2.6,4.5)^{3}$ & $0.95(1.7,6.3)^{3}$ & $1.4(6.4,2.7)^{3}$ & $0.68(4.0,4.5)^{3}$ \\
$2015\left(M_{\mathrm{w}}=8.3\right)$ & 2.71 & 2.90 & 0.73 & 0.57 & 0.22 & 0.17 \\
$1995\left(M_{\mathrm{w}}=8.0\right)$ & 1.13 & 1.03 & 0.42 & 0.15 & 0.51 & 0.15 \\
\hline
\end{tabular}

${ }^{1}$ Unfiltered.

${ }^{2}$ Band-pass filtered at $0.002-0.01 \mathrm{~Hz}$.

${ }^{3}$ Two numbers in the parentheses are the amplitude ratios of the 1922-2015, and 1922-1995 events.

Table 3. $M_{\mathrm{w}}$ of the 1922 earthquake estimated from the Hongo Omori seismograms.

\begin{tabular}{lcc}
\hline Phase used & $M_{\mathrm{w}}$ from 2015 & $M_{\mathrm{w}}$ from 1995 \\
\hline G1 (unfiltered) & 8.62 & 8.62 \\
G1 (filtered 0.002-0.01 Hz) & 8.58 & 8.44 \\
R1 (filtered 0.002-0.01 Hz) & 8.45 & 8.53 \\
G2 (filtered $0.002-0.01 \mathrm{~Hz}$ ) & 8.84 & 8.29 \\
R2 (filtered $0.002-0.01 \mathrm{~Hz}$ ) & 8.70 & 8.44 \\
\hline
\end{tabular}

period $T_{s}$, if we use $T_{s}=50 \mathrm{~s}$ instead of $T_{s}=40 \mathrm{~s}$, then the gain would be 56 per cent higher, leading to a difference of -0.13 in estimated $M_{\mathrm{w}}$. The uncertainty in the static magnification, $V$, may also have to be included. Thus, although we believe that $T_{s}=40 \mathrm{~s}$ and $\varepsilon=0.6$ used for computation of the simulated records are reasonable, considerable uncertainty is inevitable.

Furthermore, the assumption that the source durations of these events are approximately the same may not be valid, especially if $M_{\mathrm{w}}$ of the 1922 event is much larger than we thought. Thus, the estimates of $M_{\mathrm{w}}$ listed in Table 3 should be considered only tentative. Fortunately, well-calibrated Wiechert seismograms for the 1922 Atacama earthquake recorded at the Uppsala Observatory, Sweden, can be used to determine the effective gain of the Hongo Omori seismograms. We will discuss this later after we investigate the Uppsala Wiechert records.

\section{CALIBRATION}

For quantitative investigations, instrumental calibration is critically important, but it is in general very difficult for old seismograms, especially for Omori seismographs because of the absence of specific damping device. We need to know three constants, the pendulum period, $T_{s}$, damping constant, $h$, and the static magnification, $V$ (Richter 1958, p. 219). Without calibration signals on the record, we cannot determine these constants accurately. Although we can see a transient signal on the NS component that looks like a calibration pulse, the details of the calibration method used could not be found. Thus, we try to estimate the instrument constants using the recorded G1 waveform as follows, but we also use the calibration pulse and the Wiechert seismograms recorded at Uppsala, Sweden, to make sure that our calibration is approximately correct. We describe the details in the Appendix.

Since the static magnification is essentially determined by the physical setup of the seismograph, it is generally stable. Thus, we use the values listed on the ERI data sheets. However, the pendulum period can change significantly due to a slight tilt of the instrument, especially with very long period horizontal seismographs like the ones used here. The damping of the Omori seismograph is due to air and solid friction, but no standard method is available to estimate the effective damping. Kanamori et al. (2010) compared the waveforms of $\mathrm{P}, \mathrm{S}$, and surface waves between the observed and simulated Omori seismograms of the 1907 Sumatra earthquake, and decided that a damping constant $h=0.2$ is appropriate for the waves at about 10-20 s. Fig. 5a compares the G1 waveform of the 1922 seismogram with those simulated from the displacement record of the 2015 event with various $h$. The computed G1 waveforms with $h=0.1$ and 0.2 have too much reverberation compared with the observed G1 waveform. The ones with $h=0.6$ and 0.8 match the observed waveform better. Because of the limited quality of the data, this comparison is only qualitative, but is good enough to suggest that despite the absence of damping device, the effective damping of the Omori seismograph is fairly large at long period.

Now, we compare the spectrum of the 1922 G1 waveform with the $2015 \mathrm{G} 1$ waveform in more detail. Let $S(f), D(f), I(f), \hat{\dot{M}}_{0}(f)$ and $T(f)$ be, respectively, the frequency spectrum of the seismogram, displacement spectrum, the Omori instrument response, the moment rate spectrum, and the transfer function from the source to station, and the subscripts 22 and 15 indicate the 1922 and 2015 events. Then, $\mathrm{S}_{22}(f)=I(f) D_{22}(f)=I(f) T(f) \hat{\dot{M}}_{0,22}(f)$ and $D_{15}(f)=$ $T(f) \hat{\dot{M}}_{0,15}(f)$. Here we assume that the transfer function is common to the 1922 and the 2015 events. Then,

$\left|\mathrm{S}_{22}(f) / D_{15}(f)\right|=|I(\mathrm{f})|\left|\hat{\dot{M}}_{0,22}(f) / \hat{\dot{M}}_{0,15}(f)\right|$

If we further assume that $\left|\hat{\dot{M}}_{0,22}(f) / \hat{\dot{M}}_{0,15}(f)\right| \approx M_{0,22} / M_{0,15}$ (i.e. the source spectra of the 1922 and 2015 events are similar over the frequency band of our interest, $0.005-0.03 \mathrm{~Hz}$ ), we can approximately estimate the pendulum period, $T_{s}$, and the damping constant $h$ by matching the shape of $\left|S_{22}(f) / D_{15}(f)\right|$ and $|I(f)|$. The form of $I(f)$ is constrained to be that of a mechanical instrument with $T_{s}$ and $h$. We do not use the absolute amplitude but only the overall shape of the response curve.

If we assume, instead of $\left|\hat{\dot{M}}_{0,22}(f) / \hat{\dot{M}}_{0,15}(f)\right| \approx M_{0,22} / M_{0,15}$, that the source spectrum follows the $\omega$-squared spectrum with the corner frequencies $f_{c, 15}$ and $f_{c, 22}$ for the 2015 and the 1922 event, eq. (1) should be modified to

$\left|S_{22}(f) / D_{15}(f)\right| /|C(\mathrm{f})|=|I(\mathrm{f})|\left|\hat{\dot{M}}_{0,22}(f) / \hat{\dot{M}}_{0,15}(f)\right|$,

where

$|C(f)|=\left(\frac{f_{c, 22}}{f_{c, 15}}\right)^{2} \frac{1+\left(f_{c, 15} / f\right)^{2}}{1+\left(f_{c, 22} / f\right)^{2}}$

can be regarded as a correction term for the left-hand side of eq. (1).

Fig. 5(b) compares the spectral ratio computed from the 1922 Omori seismogram and the displacement record of the 2015 event with $|I(\mathrm{f})|$ computed for a mechanical seismograph with various $T_{s}$ and $h$. On Fig. 5(b), both uncorrected ratio (eq. 1) and the corrected ratio (eq. 2) are shown for comparison. For computing the correction term (3), we need to know the corner frequencies of the 2015 and the 1922 events. For computing the correction term, we use $f_{c, 15}=0.0064 \mathrm{~Hz}$ and $f_{c, 22}=0.0037 \mathrm{~Hz}$ for the 2015 and 1922 
(a)

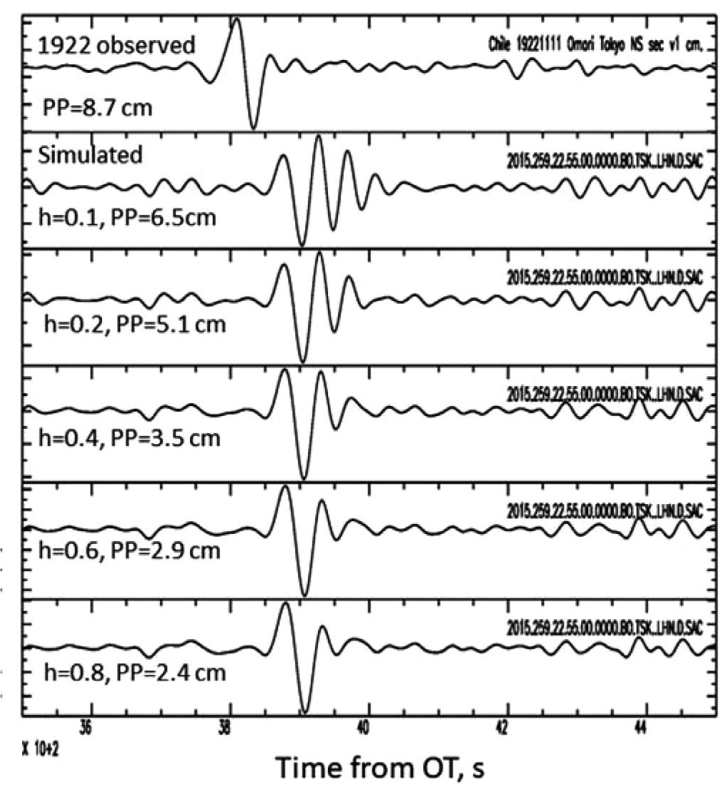

(b)

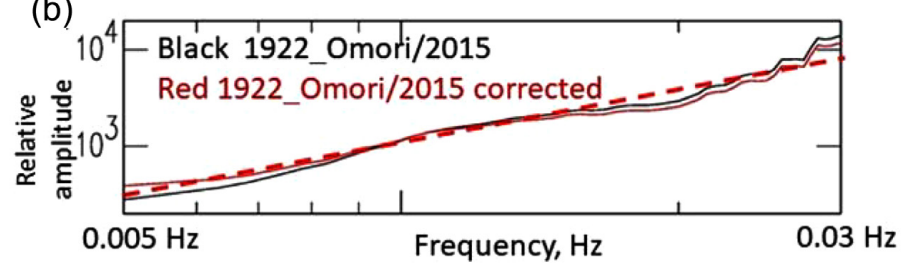

(c)

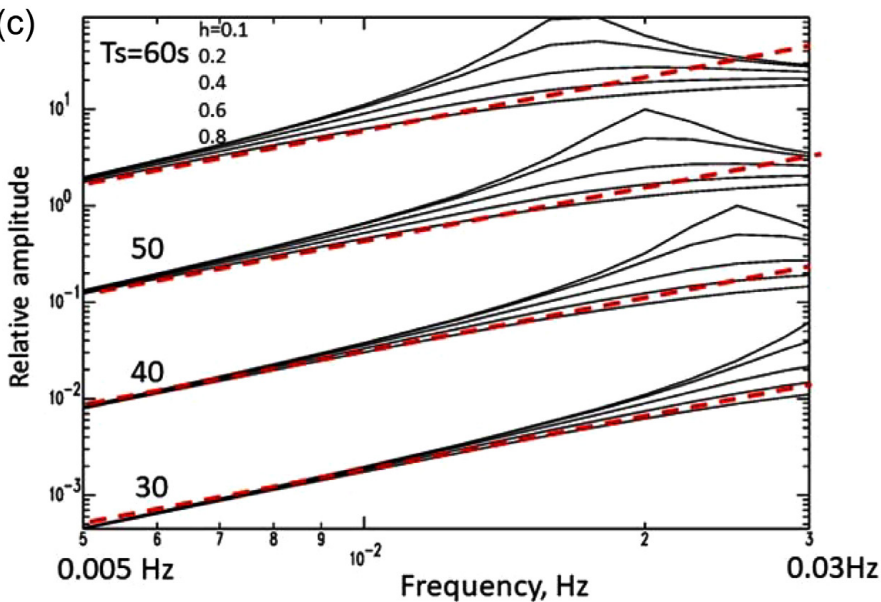

Figure 5. (a) Comparison of G1 phase of the 1922 event (top panel), with the simulated Omori seismograms computed from the 2015 event. The damping constant $h$ is varied from 0.1 to 0.8. (b) Spectral ratio of the 1922 Omori seismogram to the 2015 displacement record. Black: smoothed ratio. Red: Smoothed ratio corrected for the difference in the corner frequency. The linear trend is indicated by a broken red line. (c) Response curves for four pendulum periods, $T_{s}, 60 \mathrm{~s}, 50 \mathrm{~s}, 40 \mathrm{~s}$ and $30 \mathrm{~s}$. For each period, the response curves are computed for $h=0.1,0.2,0.4,0.6$ and 0.8 (from top to the bottom of each group). The broken red line indicates the overall trend of the observed ratio.

\section{Chile Mizusawa Omori SN}

(a)

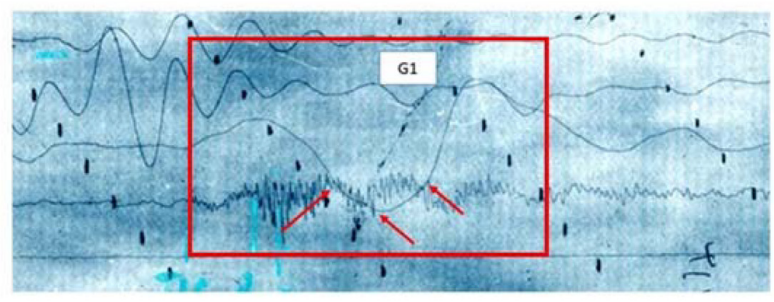

(b)

1922 Observed G1 PP=1.5 cm

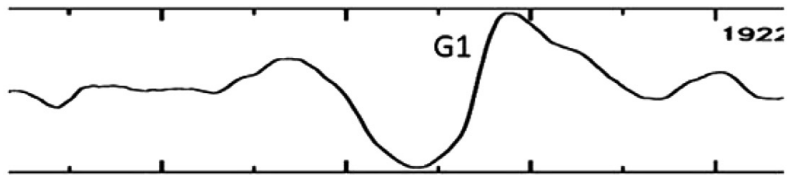

Time

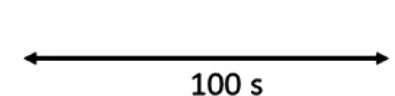

(c) $T s=37 \mathrm{~s}$ Simulated Omori from 2015 Illapel

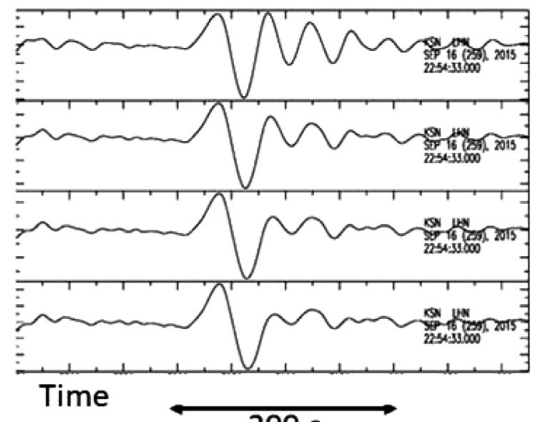

$h=0.2 \quad P P=4.7 \mathrm{~cm}$

$h=0.4 P P=3.7 \mathrm{~cm}$

$h=0.6 \quad P P=3.1 \mathrm{~cm}$

$h=0.8 \quad P P=2.6 \mathrm{~cm}$

(d)

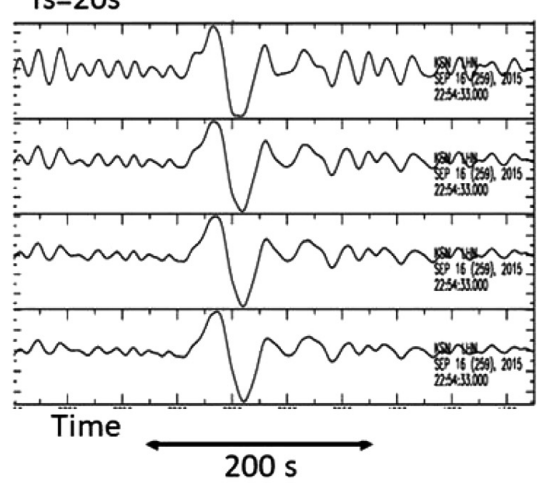

$h=0.2 \quad P P=1.2 \mathrm{~cm}$

$\mathrm{h}=0.4 \mathrm{PP}=1.0 \mathrm{~cm}$

$\mathrm{h}=0.6 \quad \mathrm{PP}=0.9 \mathrm{~cm}$

$\mathrm{h}=0.8 \quad \mathrm{PP}=0.8 \mathrm{~cm}$

Figure 6. (a) The Omori seismogram (SN component) of the 1922 Atacama, Chile, earthquake recorded at Mizusawa (MIZ). Red arrows indicate subtle kinks of the trace possibly caused by solid friction. (b) Digitized trace of (a) low-pass filtered at $0.03 \mathrm{~Hz}$. The peak-to-peak (PP) amplitude is about $1.5 \mathrm{~cm}$. (c) Simulated Omori seismograms computed from the 2015 event. The natural period is $37 \mathrm{~s}$ and the damping constant $h$ is varied from 0.2 to 0.8 . (d) Similar to (c) but the natural period is set at $20 \mathrm{~s}$. 
(a) 1922 UPP Wiechert

NS

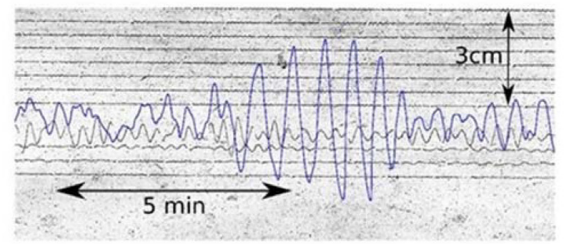

EW

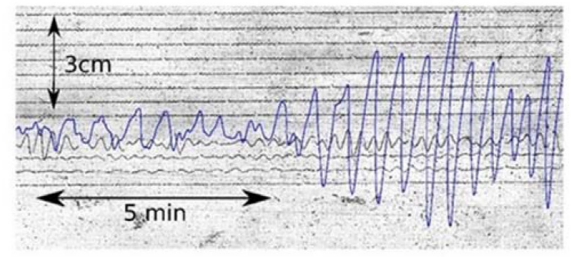

(b) Comparison of STR and UPP Wiechert records (NS)

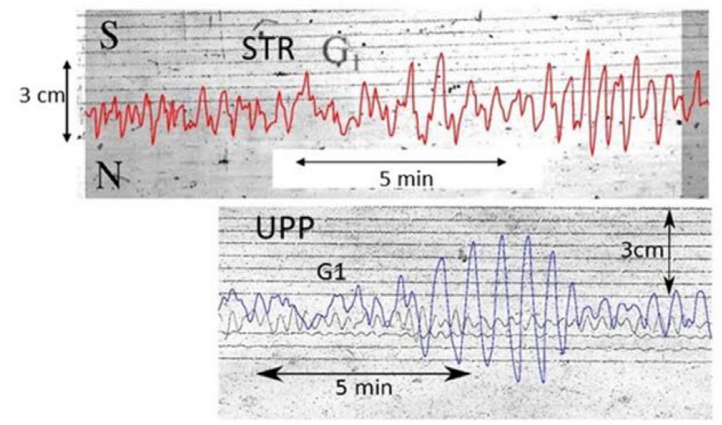

Figure 7. (a) Wiechert seismograms (NS and EW component) of the 1922 Atacama, Chile, earthquake recorded at Uppsala (UPP), Sweden. (b) Comparison of the Wiechert seismograms of the 1922 earthquake recorded at Strasbourg (STR) and UPP. Note the absence of a wave train with $30-45 \mathrm{~s}$ period on the STR record.

events, respectively. Although we do not know the corner frequency for the 1922 event, the point here is to show that the correction term is not important for our present purpose. All the curves are matched at a frequency of $0.01 \mathrm{~Hz}$, and we only compare the general trend, given by the broken red line over a frequency band from 0.005 to $0.03 \mathrm{~Hz}$. The response curves for $T_{s}=60$ and $50 \mathrm{~s}$ cannot match the overall trend of $|I(f)|$. The response curves for the cases $\left(T_{s}=40 \mathrm{~s}\right.$, $h=0.6)$ and $\left(T_{s}=30 \mathrm{~s}, h=0.6\right.$ and 0.8$)$ can match better the overall trend of $|I(f)|$. The inevitable uncertainty in the response translates to the uncertainty in the moment estimate.

We use $T_{s}=40 \mathrm{~s}, h=0.6$ and $V=20$ for the NS component of the Omori seismogram. Since we do not have a distinct phase like G1 on the EW component, we cannot perform this analysis for the EW component, and we use $T_{s}=40 \mathrm{~s}, h=0.6$ and $V=15$ for the EW component. The simulated seismograms shown in Figs 3 and 4 are computed with these response parameters.

\section{MIZUSAWA OMORI SEISMOGRAMS}

The 1922 event was also recorded with Omori Seismographs at Mizusawa (MIZ, 39.130, $141.130^{\circ}$ ) Japan. A long-period G wave was clearly recorded on the NS component seismogram (Figs 6a and $b$ ). The nominal instrument constants are as follows (International Latitude Observatory at Mizusawa, Seismological Observations 1984, pp. 379).

Omori Seismograph NS component: $T_{s}=37 \mathrm{~s}, V=20$, Mass $=17.6 \mathrm{~kg}$, paper speed $25.4 \mathrm{~mm} \mathrm{~min}^{-1}$

We perform a similar analysis to that applied to the Hongo seismogram. We use the broad-band record of the 2015 Illapel earthquake recorded at an F-net station Kesen-numa (KSN, 38.976 ${ }^{\circ}$, $\left.141.530^{\circ}, 260 \mathrm{~m}\right)$. No broadband records are available for the 1995 Antofagasta earthquake from this station.

Figs 6(a), (b) and (c) compare the observed waveform with the simulated seismograms computed with $T_{s}=37 \mathrm{~s}$ and damping constant $h$ from 0.2 to 0.8 . Unfortunately, a close examination of Fig. 6(a) reveals some distortion of the waveform with a few minor kinks which could be due to solid friction. As a result, the observed waveform is slightly longer period than any of the simulated waveforms. Because of this difficulty, we cannot estimate $T_{s}$. Considering the possibility that $T_{s}$ was a little shorter than nominal value listed in the station bulletin, Fig. 6(d) compares the observed waveform with the simulated waveforms computed with $T_{s}=20 \mathrm{~s}$ with varying $h$. For both $T_{s}=37 \mathrm{~s}$ and $T_{s}=20 \mathrm{~s}$ cases, the simulated waveforms with $h=0.6$ and 0.8 match the observed waveform better. The amplitude ratios of observed/simulated are $0.48,0.58,1.7$ and 1.9 for $\left(T_{s}=37 \mathrm{~s}, h=0.6\right),\left(T_{s}=37 \mathrm{~s}, h=0.8\right),\left(T_{s}=20 \mathrm{~s}, h=0.6\right)$ and $\left(T_{s}=20 \mathrm{~s}, h=0.8\right)$, respectively. Given $M_{\mathrm{w}}=8.3$ for the 2015 Illapel earthquake, these ratios suggest an $M_{\mathrm{w}}=8.1$ to 8.5 for the 1922 event, but because of the somewhat distorted waveform of the Mizusawa Omori seismogram (Fig. 6), this estimate is less reliable than that estimated from G1 of the Hongo Omori seismogram.

\section{UPPSALA (UPP) AND STRASBOURG (STR) WIECHERT SEISMOGRAMS}

Motivated by Okal's (1992) spectral results we investigate the Uppsala Wiechert seismograms of the 1922 event kindly made available to us by the Uppsala Observatory $\left(59.858^{\circ}, 17.623^{\circ}\right)$, Sweden, (www.snsn.se/network, doi: 10.18159/SNSN).

Fig. 7(a) shows the NS and EW components of the UPP Wiechert seismograms which include the main part of G1 and R1, respectively. Because the Wiechert seismographs are much shorter period than the Omori seismographs, we do not see clear long-period G1 and R1 on these records. However, because of the instrument damping, the response of the Wiechert seismographs is better defined. In particular, the response of the Wiechert seismographs at UPP were kept constant (e.g. Kulhanek \& Wahlstrøm 1996). Here we use the constants given by Charlier \& Van Gils (1953): NS $T_{s}=9.5 \mathrm{~s}$, $\varepsilon=3.5, V=183$; EW $T_{s}=8.7$ s. $\varepsilon=3.5, V=186$. We digitized these records after correcting for the curvature and slant (Cedek 1987). As shown in Fig. 7(a), the slant of the EW record is very large and may inevitably introduce long-period noise.

We use essentially the same method as that used for the analysis of the Hongo Omori records. We simulated Wiechert seismograms at UPP for the 2015 Illapel, Chile, earthquake using the broadband records from Uppsala (Böðvarsson \& Lund 2003). For the 1995 Antofagasta, Chile, earthquake, since the records at UPP are not available, we use the broadband records from the station KONO. 
(a) UPP Wiechert NS
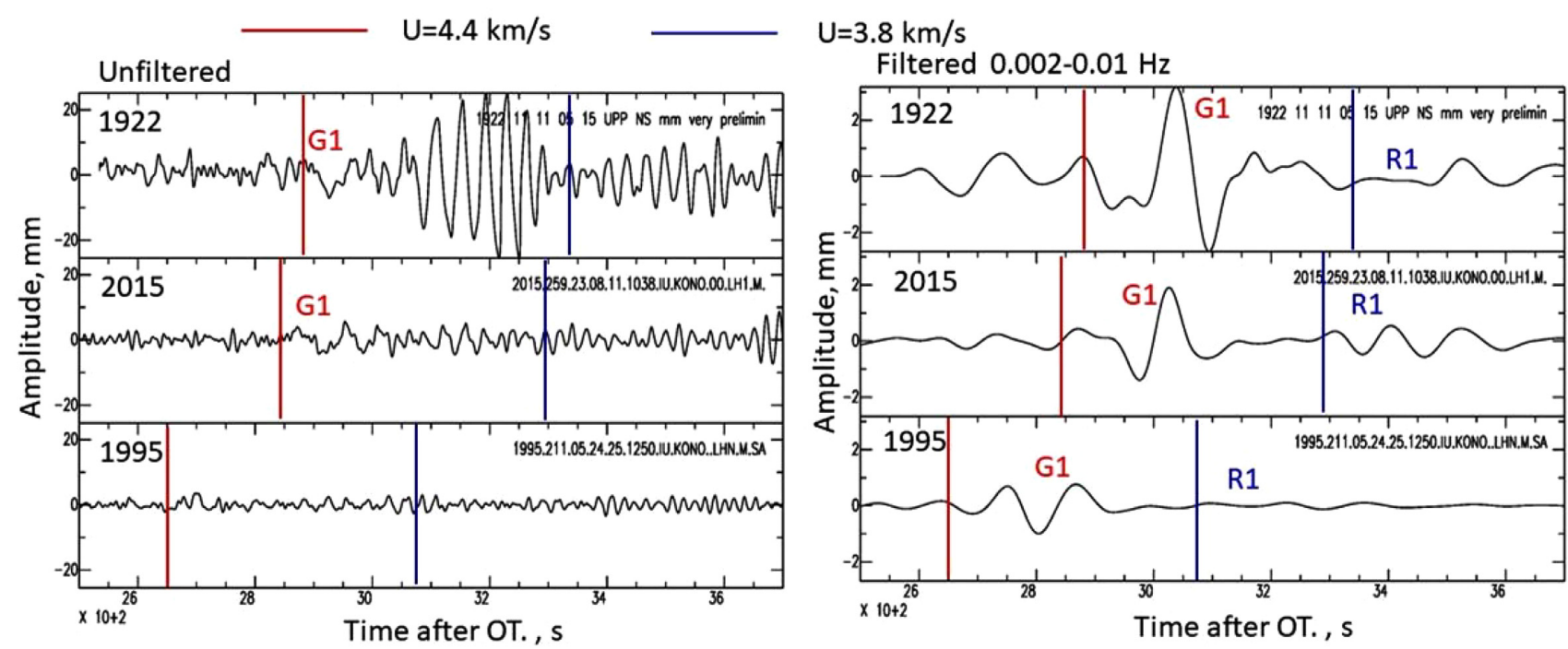

(b) UPP Wiechert EW
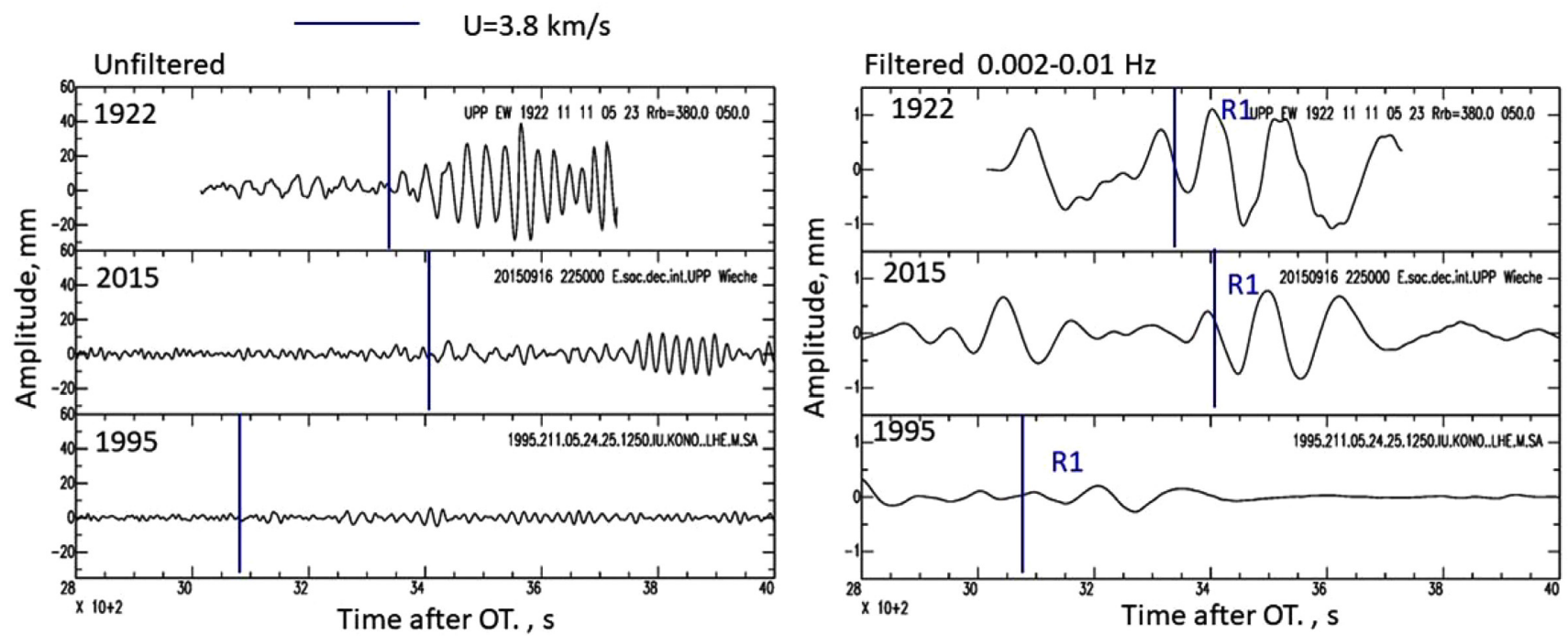

Figure 8. Comparison of the UPP Wiechert seismograms of the 1922, 2015 and 1995 Chile earthquakes. Red vertical lines indicate the group arrival time of G1 with $U=4.4 \mathrm{~km} \mathrm{~s}^{-1}$, and blue vertical lines indicate the group arrival time of R1 with $U=3.8 \mathrm{~km} \mathrm{~s}^{-1}$. (a) Left-hand panel: unfiltered records of the NS component. Right-hand panel: bandpass-filtered $(0.002-0.01 \mathrm{~Hz})$ records. (b) Similar to (a) for the EW component.

Table 4. Event-station data. epicentre (latitude, longitude), station (latitute, longitude), distance, azimuth and backazimuth.

\begin{tabular}{lccccccc}
\hline Event-Station & Lat_e $\left({ }^{\circ}\right)$ & Long_e $\left({ }^{\circ}\right)$ & Lat_s $\left({ }^{\circ}\right)$ & Long_s $\left({ }^{\circ}\right)$ & $\Delta\left(^{\circ}\right)$ & $\phi\left({ }^{\circ}\right)$ \\
\hline 1922-UPP & -28.91 & -70.87 & 59.858 & 17.623 & 113.80 & 33.47 \\
1995-KONO & -24.17 & -70.74 & 59.649 & 9.598 & 104.85 & 31.14 & 253.32 \\
2015-UPP & -31.13 & -72.09 & 59.858 & 17.623 & 116.39 & 34.29 \\
1922-STR & -28.91 & -70.87 & 48.584 & 7.766 & 104.28 & 42.32 \\
\hline
\end{tabular}

Figs 8(a) and (b) compare the 1922, 2015 and 1995 events. Table 4 lists the relevant event-station data. The traces on the left figures are unfiltered records, and those on the right figures are the band-pass filtered (from 0.002 to $0.01 \mathrm{~Hz}$ ) records. Although the unfiltered traces show that the 1922 event is considerably larger than the 2015 and the 1995 event, no distinct phases can be identified. However, on the filtered traces, G1 on the NS component, and R1 on the EW component can be clearly seen at approximately the correct group arrival times (red and blue vertical lines indicate the group arrival times for 4.4 and $3.8 \mathrm{~km} \mathrm{~s}^{-1}$, respectively). However, the peak-topeak (PP) amplitudes on the bandpass filtered records are less than a few $\mathrm{mm}$, probably close to the resolution limit. In particular, the $\mathrm{R} 1$ on the EW component is noisy and may not be reliable. Another 
Table 5. Peak-to-peak amplitude (in mm) of G1 (on NS), and R1 (on EW) at UPP.

\begin{tabular}{lcc}
\hline Event & G1 (NS) & R1(EW) \\
\hline $1922\left(M_{S}=8.3\right)$ & $5.54(1.9,2.9)^{2}$ & $2.19(1.4,4.6)^{2}$ \\
$2015\left(M_{\mathrm{w}}=8.3\right)$ & 2.88 & 1.61 \\
$1995\left(M_{\mathrm{w}}=8.0\right)$ & 1.89 & 0.474 \\
\hline
\end{tabular}

${ }^{1}$ Bandpass filtered at $0.002-0.01 \mathrm{~Hz}$.

${ }^{2}$ Two numbers in the parentheses are the amplitude ratios of the 1922-2015, and 1922-1995 events.

question is the effect of solid friction at long period (e.g. $100 \mathrm{~s}$ ) which may diminish the amplitude.

The most conspicuous features of the unfiltered records of both G1 and R1 (Figs 7a and b) are the large amplitude short-period (30$45 \mathrm{~s}$ ) waves of the 1922 record which are absent for the other 2 events (Figs $8 \mathrm{a}$ and $\mathrm{b}$ ). On the bandpass filtered records, the waveforms are similar, and the amplitude ratio can be a more reliable measure of the difference in the moment. Table 5 summarizes the amplitude ratios of G1 and R1. These ratios are slightly smaller than those obtained from the Hongo Omori records (Table 2), but given the uncertainties in the response and noise, the result is by and large consistent with that from the Hongo records.

The large amplitude wave train with periods from 30 to $45 \mathrm{~s}$ on the UPP records of the 1922 event is probably due to focusing effects and is not due to source effects. For comparison, on Fig. 7(b), we show a Wiechert seismogram of the 1922 event recorded at Strasbourg (STR, $\Delta=104.281^{\circ} ; \phi=42.321^{\circ}$ ). Even if the distance and azimuth differences between UPP and STR are only $9.6^{\circ}$ and $10^{\circ}$, respectively, we do not see this large wave train on the STR record. For further comparison, Fig. 9(a) shows the spectrum of the NS component of the 1922 Omori seismogram at Hongo, the spectrum of the simulated Omori seismogram for the 2015 event at TSK, and the 1922/2015 spectral ratio. Fig. 9(b) shows similar spectra and the ratio for the UPP Wiechert records. A prominent peak at about $45 \mathrm{~s}$ for the UPP record is evident, but no such peak is visible for the Hongo Omori record. Thus, in general, we should not use the waves at period shorter than $50 \mathrm{~s}$ for moment estimation. Judging from the response of the Omori seismograph and the Wiechert seismograph, we believe that the amplitude measurements are reliable at the period of about $100 \mathrm{~s}$, and 100-150 s on the Wiechert and Omori seismograms, respectively.

So far we have compared the amplitudes on the time-domain; here we combine the spectral measurements of the most reliable records, the Hongo G1 and UPP G1. Fig. 9 shows that, if our calibration is correct, the 1922/2015 Hongo Omori spectral ratio varies from 2.2 to 2.5 over a period of $100-150 \mathrm{~s}$, and the $1922 / 2015$ UPP Wiechert spectral ratio is about 1.9 at a period of about $100 \mathrm{~s}$. Fig. 10 shows these ratios together with the omega-squared momentrate spectrum of $M_{\mathrm{w}}=8.6,8.75$ and 8.9 events normalized by that of an $M_{\mathrm{w}}=8.3$ event. In this computation the corner frequency is given by $f_{c}=1 /\left(\pi t_{c}\right)$ where $t_{c}=2.6 \times 10^{-5} M_{0}^{1 / 3}\left(M_{0}\right.$ in Nm, Duputel et al. 2013). We intend to make two points with this comparison. First, since the calibration of the UPP Wiechert seismogram is reliable at $100 \mathrm{~s}$, the good agreement between the spectral ratios from Hongo and UPP suggests that the calibration we made for the Omori seismogram with somewhat incomplete information and some assumptions is approximately correct. Secondly, as we suggested from the time-domain amplitude ratios, the 1922 event is significantly larger than the 2015 event $\left(M_{\mathrm{w}}=8.3\right)$, but is not much larger than $M_{\mathrm{w}}=8.7$ because the observed ratios fall in between the curves for $M_{\mathrm{w}}=8.6$ and $M_{\mathrm{w}}=8.75$.

\section{Zi-ka-wei WIECHERT SEISMOGRAM}

Another useful record of the 1922 event is R1 phase recorded on a Wiechert seismogram at Zi-ka-wei (ZIK, $31.200^{\circ}, 121.433^{\circ}$ ), China, shown in Fig. 11. The instrument constants for the period from $6 / 22 / 1922$ to $1 / 2 / 1923$ are given in the station bulletin as EW $T_{s}=10.0 \mathrm{~s}, \varepsilon=3.5, V=151$, and the recording paper speed is $15 \mathrm{~mm} \mathrm{~min}^{-1}$. It is rare to see long-period waves on Wiechert seismograms with a relatively short pendulum period, $10 \mathrm{~s}$.

Fig. 11(a) shows a long-period wave train (Red) on the EW component of the Zi-ka-wei seismogram. Fig. 11(b) shows the trace digitized from the original trace and a simulated Wiechert seismogram computed from the 2015 Illapel earthquake seismogram recorded at station Sheshan (SSE, 31.095 $\left., 121.191^{\circ}, 40 \mathrm{~m}\right)$. Fig. 11(c) shows the same records after a bandpass filter $(0.002-0.01 \mathrm{~Hz})$ has been applied. The vertical blue lines indicate the group arrival times for $3.8 \mathrm{~km} \mathrm{~s}^{-1}$ for R1 and R2. On the unfiltered record (Fig. 11b) the similarity between the 1922 and 2015 records is poor. However, we can see some correspondence between the observed and simulated records, though the waveforms are somewhat different. However, since we seldom see long-period waves on $10 \mathrm{~s}$ Wiechert seismograms, we are not sure how good the Wiechert seismograph with a $10 \mathrm{~s}$ pendulum with a smoked paper drum is for recording very long-period waves. The overall amplitude of the observed record is approximately twice that of the simulated record (Table 6), but because of the mismatch of the waveform between the observed and simulated seismograms, we cannot make a definitive conclusion except that the 1922 event is probably considerably larger than the 2015 event.

\section{$7 P$-WAVE OBSERVATION AT DE BILT}

Beck et al. (1998) demonstrated that the $P$ wave of the 1922 event on the vertical component of a Galitzin seismogram at De Bilt (DBN) is much larger and more complex than that of the 1943 event (fig. 4 of Beck et al. 1998). Since the vertical component record on the DBN seismogram is difficult to trace because of the large amplitude, we compare the horizontal component records in Fig. 12. Qualitatively, Fig. 12 is consistent with Beck et al.'s fig. 4. Fig. 12 also shows the $\mathrm{P}$ wave of the 1995 and 2015 events. Since the distance range, $100^{\circ}$ to $107^{\circ}$, brackets the beginning of the core shadow zone, the amplitude behavior can be complicated; thus we do not compare the absolute amplitude, and compare only the overall character of the $P$ waveforms.

The comparison of the 1922 and the 1943 events is consistent with Beck et al.'s observation. However, the duration of the 1995 event which is presumably much smaller than the 1922 event is comparable to that of the 1922 event. Also, the $P$-wave train of the 2015 event is of much shorter period and the duration is much shorter than either the 1922 or 1943 event. For the 1995 and the 2015 events, the duration of the moment rate function has been estimated from long-period waves and body wave slip inversion. The GCMT solutions list $t_{c}$ (centroid time minus hypocentre time) $=50$ and $33.4 \mathrm{~s}$ for the 2015 and the 1995 event, respectively. In general, $2 t_{c}$ can be taken as the source duration (Duputel et al. 2013). As shown on Fig. 12, the duration of the $P$ wave train does not necessarily indicate the source duration and the overall size of the events. Nevertheless, the variability of the duration and complexity of the $P$ waveforms is interesting because it suggests that these events are significantly different in the radiation of short-period energy. 
(a) Hongo NS component G1

(b) UPP NS component G1
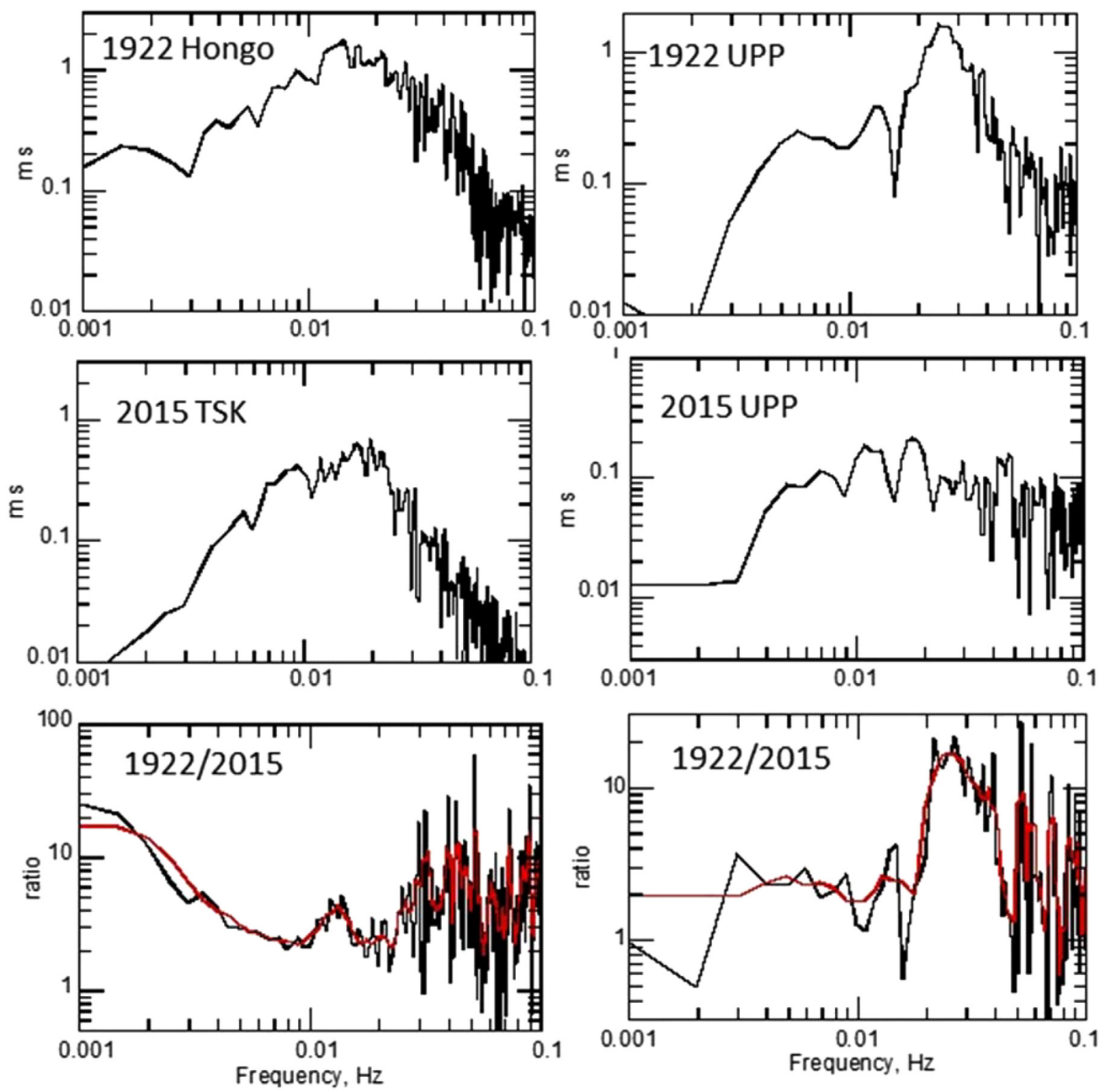

Figure 9. (a) Top panel: spectrum of the NS component of the 1922 Hongo Omori seismogram (unit: $\mathrm{m}$ s). Middle: The NS component Omori seismogram of the 2015 event simulated from a broadband record at TSK (unit: $\mathrm{m} \mathrm{s}$ ). Bottom panel: the spectral ratio (top)/(middle). The red curve shows a smoothed ratio. (b) Similar to (a) computed for the UPP Wiechert seismograms.

\section{SURFACE-WAVE MAGNITUDE}

Although surface-wave magnitude, $M_{S}$, is not widely used in modern earthquake seismology, it is a useful observed parameter for comparing historical events with recent events. However, because of the complex path effects, the azimuthal variation of $M_{S}$ is often very large (larger than $1.5 M_{S}$ unit), and it is important to consider $M_{S}$ values spanning a wide azimuthal range rather than just considering the average value. Fortunately, Gutenberg documented his $M_{S}$ measurements from many stations in his notepad (Goodstein et al. 1980) used for Gutenberg \& Richter (1954). Fig. 13 compares Gutenberg's $M_{S}$ values for the 1922 event with those for the 1995 and 2015 events we determine from the global data. We use the vertical component records and the IASPEI formula (Vanek et al. 1962). Although the formula used by Gutenberg and the Vanek et al.'s formula yield a slightly different numerical $M_{S}$ value, given the ambiguities involved in the definition of the horizontal component, the presence of Love waves, the period measurements, we ignore it because the difference is probably smaller than the uncertainty in the individual measurement (Geller \& Kanamori 1977; Lienkaemper 1984). The average and median values of $M_{S}$ are both
7.8 for the 2015 event, and 7.6 and 7.5 for the 1995 event. The $M_{S}$ values for the 1922 event are consistently larger than either the 1995 or 2015 event. In general, for most large events with $M_{S} \geq 8, M_{\mathrm{w}}$ is larger than $M_{S}$ (Fig. 14). Since $M_{S}=8.3$ (Abe 1981), the $M_{\mathrm{w}}$ of the 1922 event is most likely larger than 8.5 , and $M_{\mathrm{w}}=8.6$ estimated from the Hongo Omori seismogram is reasonable.

\section{DISCUSSION AND CONCLUSION}

Interpretation of old seismograms, especially Omori seismograms without damping, is difficult because of the uncertainties in the instrument constants, and possible instrumental defects. Among all the records we used, the Hongo Omori seismograms are probably most reliable. From Table 3 , the $M_{\mathrm{w}}$ estimates from G1 and R1 phases from the Hongo Omori seismograms range from 8.29 to 8.84 . This range is consistent with the value inferred from the surface-wave magnitude $M_{S}=8.3$ (Fig. 13) and the $M_{S}$ versus $M_{\mathrm{W}}$ relation shown in Fig. 14. With a small number of old seismograms with uncertain instrumental characteristics, it is difficult to give an accurate estimate of $M_{\mathrm{w}}$, but we believe that a reasonable range is 


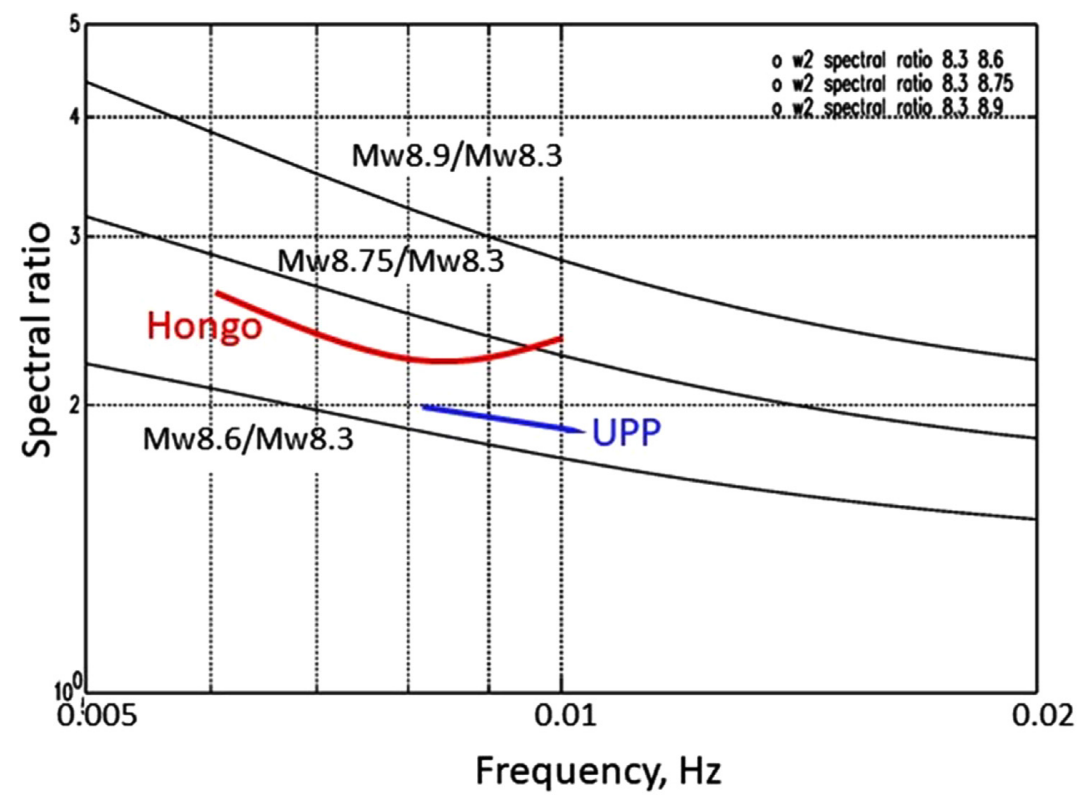

Figure 10. The ratio of the omega-squared moment rate spectrum for $M_{\mathrm{w}}=8.9$ to $8.3, M_{\mathrm{w}}=8.75$ to 8.3 . and $M_{\mathrm{W}}=8.6$ to 8.3 , and the observed spectral amplitude ratio of the 1922 record to the simulated 2015 record at Hongo (red) and UPP (blue). The observed 1922/2015 spectral ratio at UPP is 1.9 at $100 \mathrm{~s}$, and that at Hongo is $2.2-2.5$ over a period of $100-150 \mathrm{~s}$.

(a) 1922 Observed

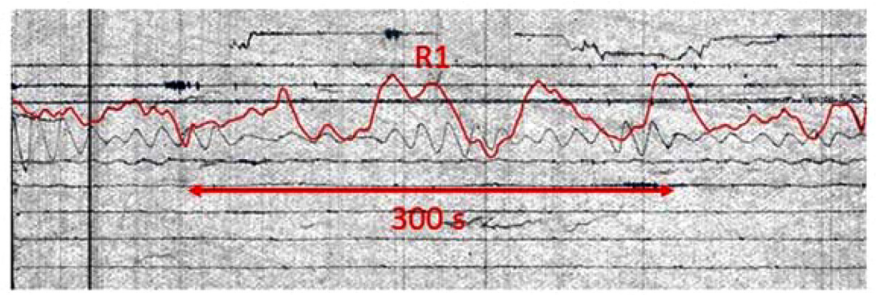

(b)

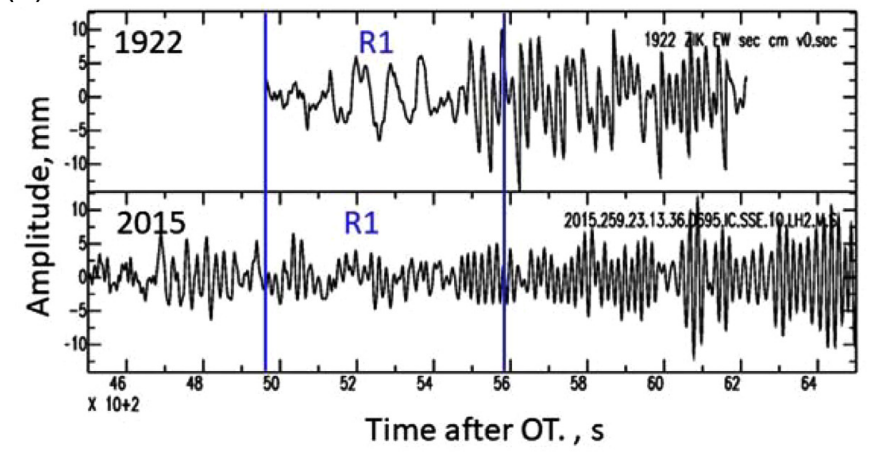

(c)

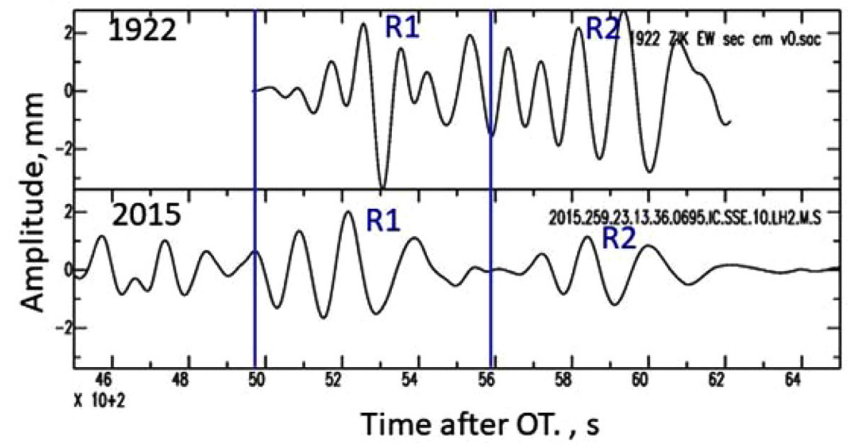

Figure 11. (a) The Wiechert seismogram (EW component) of the 1922 Atacama earthquake recorded at Zi-ka-wei (ZIK). The trace highlighted by red is R1. (b) Top panel: digitized trace of (a). Bottom panel: simulated Wiechert seismogram computed from the broadband seismogram of the 2015 Illapel earthquake recorded at station Sheshan (SSE). Both records are low-pass filtered at $0.03 \mathrm{~Hz}$. The peak-to-peak amplitude of R1 on the $1922 \mathrm{record}$ is $1.2 \mathrm{~cm}$. (c) The same records as shown in (b), but bandpass filtered at $0.002-0.01 \mathrm{~Hz}$.

Table 6. Peak-to-peak amplitude (in $\mathrm{mm}$ ) of R1 and R2 at Zi-ka-wei.

\begin{tabular}{lcc}
\hline Event & $\mathrm{R} 1(\mathrm{EW})^{1}$ & $\mathrm{R} 2(\mathrm{EW})^{1}$ \\
\hline $1922\left(M_{S}=8.3\right)$ & $5.67(1.5)^{2}$ & $5.57(2.2)^{2}$ \\
$2015\left(M_{\mathrm{w}}=8.3\right)$ & 3.87 & 2.51 \\
\hline
\end{tabular}

${ }^{1}$ Bandpass filtered at $0.002-0.01 \mathrm{~Hz}$.

${ }^{2}$ The number in the parentheses is the amplitude ratio of the 1922-2015 events.
$8.6 \pm 0.25$. The tsunami associated with the 1922 Atacama earthquake was large and Abe (1979) gave a tsunami magnitude $M_{t}=8.7$. Since $M_{t}$ is adjusted to be comparable to $M_{\mathrm{w}}$ on average, the approximate agreement between $M_{t}$ and $M_{\mathrm{w}}$ for the 1922 event indicates that it was most likely a typical megathrust earthquake rather than an unusual tsunami earthquake. Carvajal et al. (2017a) estimated $M_{\mathrm{w}}=8.5-8.6$ based on comparison of tsunami amplitudes in Japan calibrated for recent South American events. Okal (1992) obtained $M_{m}=8.56-8.61 . M_{\mathrm{w}}=8.6 \pm 0.25$ is also compatible with the estimate of rupture length being 300-450 km from Kelleher (1972), 


\section{Comparison of P wave De Bilt Galitzin}
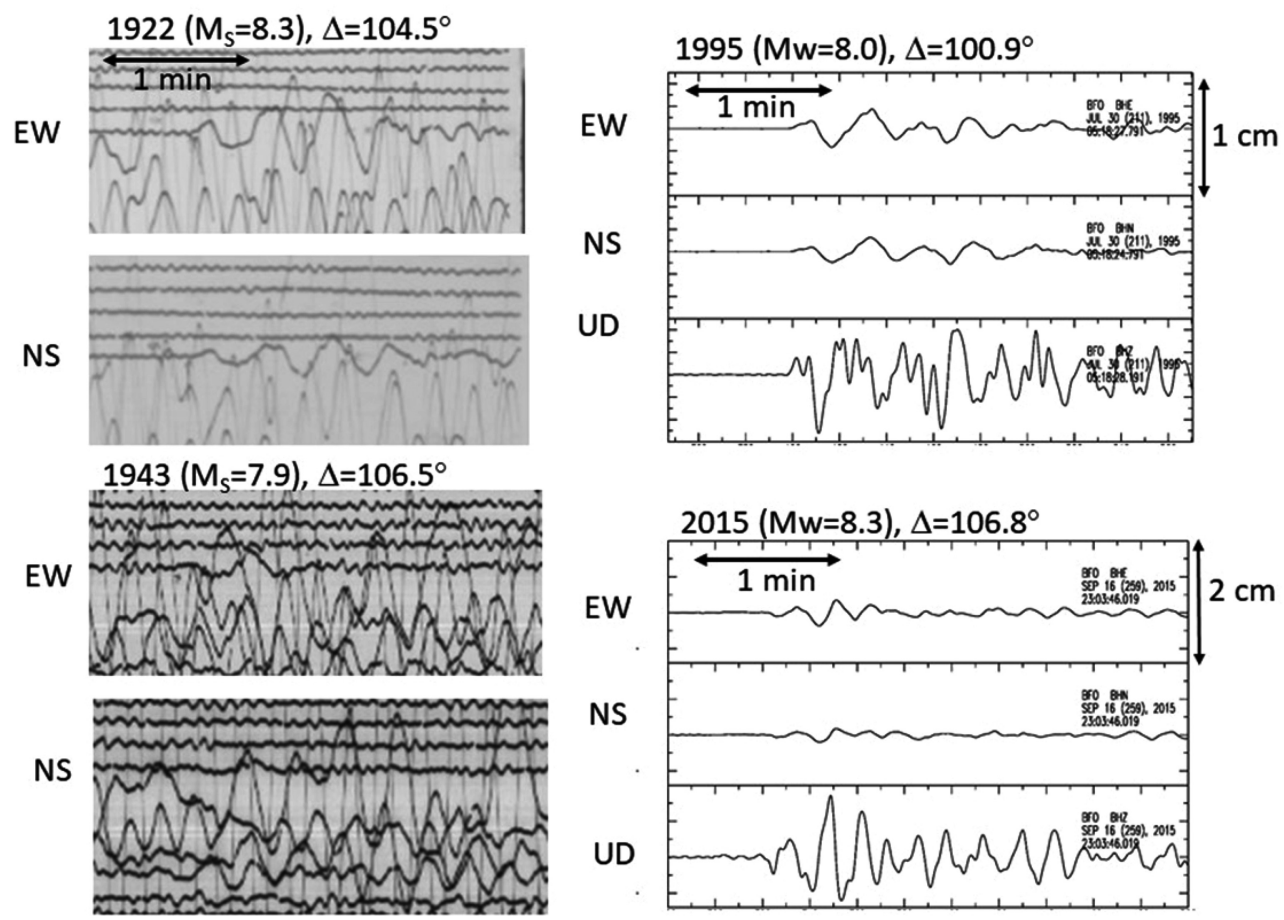

Figure 12. Comparison of $P$ wave of the 1922 (Atacama), the 1943 (Illapel), the 1995 (Antofagasta) and the 2015 (Illapel) earthquakes. The 1922 and the 1943 earthquakes were recorded with the Galitzin seismograph at De Bilt, and the 1995 and the 2015 events were recorded at Black Forest (BFO). The 1995 and the 2015 seismograms are simulated from the broadband seismograms.

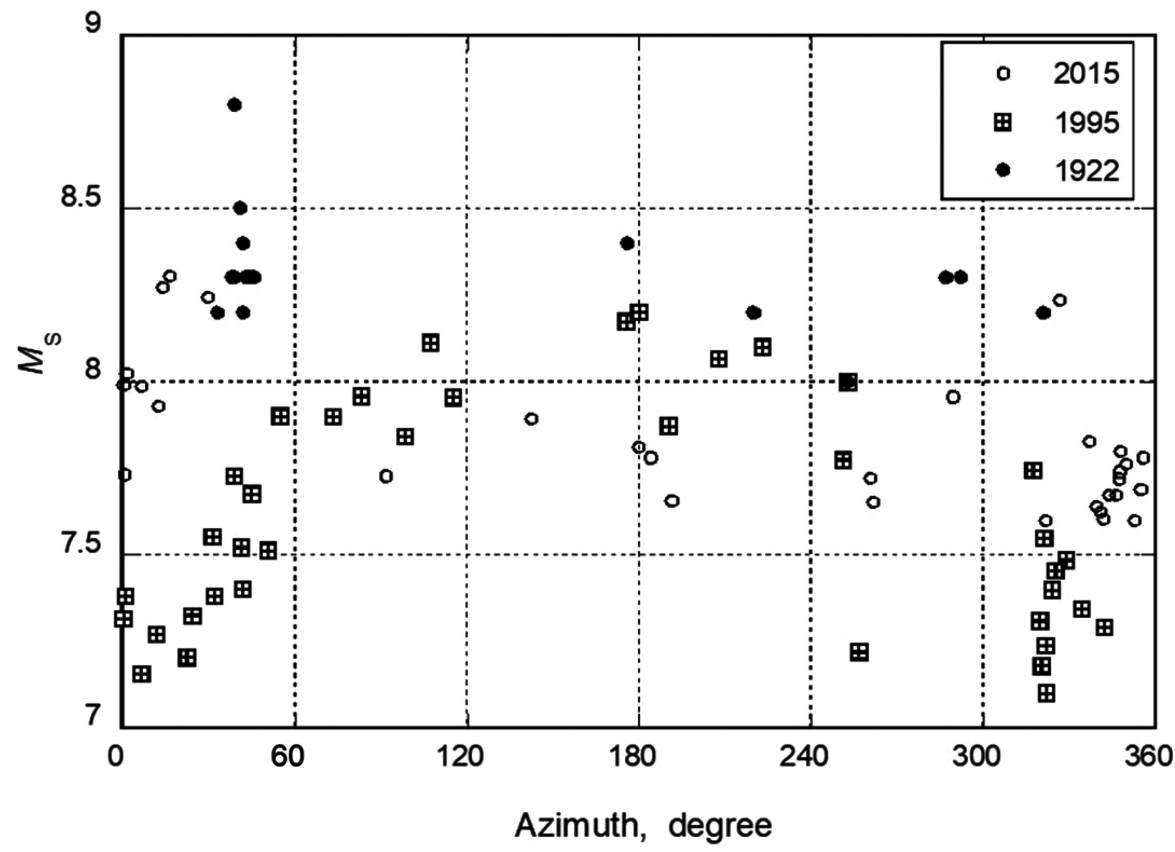

Figure 13. Surface-wave magnitude, $M_{S}$, of the 1922 Atacama, the 1995 Antofagasta and the 2015 Illapell earthquakes. $M_{S}$ for the 1995 and the 2015 events are computed from the vertical component records using the IASPEI formula. $M_{S}$ values for the 1922 event are from Gutenberg's notepad.

who used S-P data from La Paz to constrain the aftershock distribution, along with the observations of coastal uplift, shaking damage and tsunami run-up from Willis (1929). Reports of delayed arrival of the tsunami relative to the shaking by $2 \mathrm{hr}$ in Coquimbo and 1 hr at Chañaral (Soloviev \& Go 1975) tend to support the shorter length, at least for slip offshore. Kanamori (1977) inferred $M_{\mathrm{w}} 8.5$ from Kelleher's (1972) rupture area.

Our preferred estimate of $M_{\mathrm{w}}$ for the 1922 Atacama event is larger than the $M_{\mathrm{w}}$ of the 2015 Illapel and the 1995 Antofagasta earthquakes, which is consistent with the larger rupture dimension of the 1922 event estimated by Gutenberg (1924) and Kelleher 


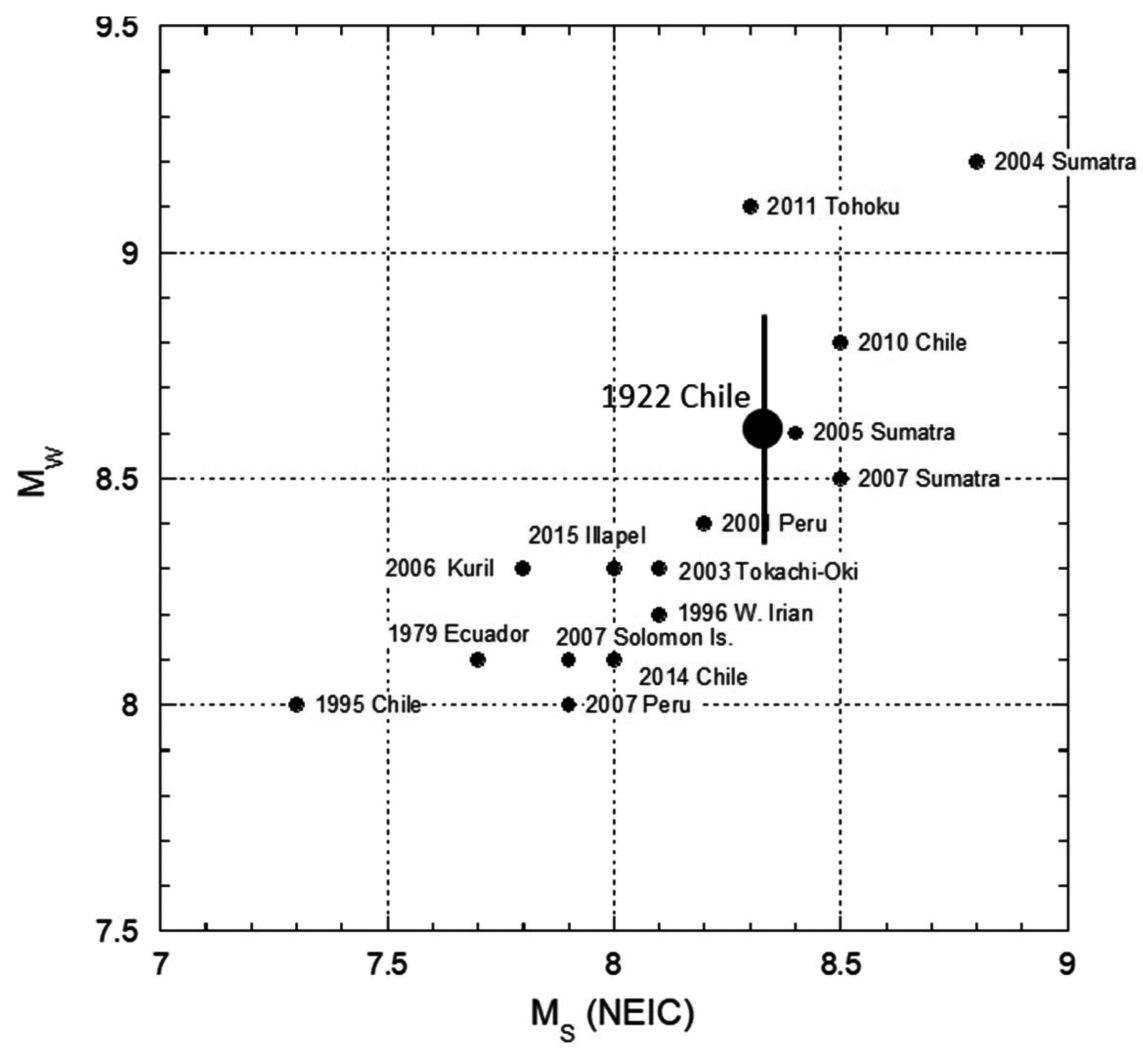

Figure 14. Comparison of $M_{S}$ and $M_{\mathrm{W}}$ of $M_{\mathrm{W}} \geq 8$ megathrust earthquakes. $M_{S}$ values are from the NEIC catalogue and $M_{\mathrm{w}}$ values are from the GCMT catalogue except for the 2004 Sumatra earthquake. $M_{\mathrm{w}}=9.2$ used for the Sumatra earthquake is the average of commonly used values. The estimated $M_{\mathrm{w}}$ for the 1922 event is shown by an open circle with the estimated uncertainty. The $M_{S}$ value for the 1922 event is from Abe (1981).

(1972). However, the $P$ waves from the 1922, 1943 (Illapel), 1995 and 2015 events suggest that the slip zones are spatially complex, and depending on how the rupture is initiated, the overall rupture behavior may vary from one sequence to another. Such variability has been seen for the rupture sequences along the Ecuador-Colombia subduction-zone (e.g. Kanamori \& McNally 1982) and the Nankai subduction zone in Japan (e.g. Imamura 1928; Ando 1975).

Recent GPS results indicate that the 1922 rupture zone is accumulating slip deficit with some along-strike patchiness (Métois et al. 2016). Several large-slip patches may have failed in 1922 based on the $P$ wave analysis of Beck et al. (1998). The northern region of the 1922 rupture zone from $26^{\circ} \mathrm{S}$ to $27^{\circ} \mathrm{S}$ has experienced relatively frequent large ruptures in $1796(M \sim 7.5), 1819(M$ $\sim 8.5), 1859$ ( $M \sim 7.5), 1918$ ( $M \sim 7-7.5), 1922$ and 1983 ( $\left.M_{\mathrm{w}} 7.6\right)$, while the southern region from $27^{\circ} \mathrm{S}$ to $29.5^{\circ} \mathrm{S}$ appears to have ruptured only in 1819 and 1922 (Comte et al. 2002; Lomnitz 2004; Ruiz \& Madariaga 2018, Fig. 1). Modeling of the rupture extent of the 1730 event to the south, along Valparaíso, indicates that there may be no overlap with the 1922 rupture (Carvajal et al. 2017b). Beck et al. (1998) infer that the 1796/1819 and 1918/1922 event pairs are the primary plate boundary ruptures, with the inter-event time suggesting substantial strain accumulation of the 1922 zone is likely, particularly in the region south of the 1983 rupture. The confirmation of the large $M_{\mathrm{w}}$ for the 1922 event provided here reinforces the high seismic hazard of the Atacama segment of the plate boundary.ACKNOWLEDGEMENTS

\section{ACKNOWLEDGEMENTS}

The Omori seismograms used in this study were made available to us by the historical seismogram archive at the Earthquake Research Institute, the University of Tokyo. We thank Kenji Satake and the staff of the archive. We thank Toru Matsuzawa and Tomotsugu Demachi at Tohoku University for making available to us the Mizusawa Omori seismograms, and Bernard Dost at the Royal Netherlands Meteorological Institute, Susan Beck at the University of Arizona and Björn Lund at Uppsala University for helping us study De Bilt seismograms and Uppsala seismograms (1922 and 2015). We thank Javier Ruiz at the Universidad de Chile for helping us locate Sieberg \& Gutenberg (1924), and Nobuo Hamada for prividing us with a copy of the Observatory Manual of the Central Meteorological Agency, Japan, published in 1936. The copies of the Gutenberg notepad used in this study are provided by the Archives of the California Institute of Technology. The Data Management System of the Incorporated Research Institutions for Seismology (http://www.iris.edu/hq/) was used to access the seismic data from the Global Seismic Network and Federation of Digital Seismic Network stations. The F-net data used in this study were provided by the National Research Institute for Earth Science and Disaster Prevention (NIED) of Japan. T. Lay's research on earthquakes is supported by U.S. National Science Foundation grant EAR1802364. L. Ye's research on earthquakes is supported by National Science Funding of China (NSFC) grant No. 41874056. We thank the editor, Dr. Huajian Yao, and two anonymous reviewers for encouraging comments on our manuscript. 


\section{REFERENCES}

Abe, K., 1979. Size of great earthquakes of 1837-1974 inferred from tsunami data, J. geophys. Res.: Solid Earth, 84, 1561-1568.

Abe, K., 1981. Magnitudes of large shallow earthquakes from 1904 to 1980, Phys. Earth planet. Inter, 27, 72-92.

Agnew, D.C., 2002. History of seismology, International Handbook of Earthquake and Engineering Seismology, Vol. 81, pp. 3-11.

An, C., Yue, H., Sun, J., Meng, L. \& Báez, J.C., 2017. The 2015 M w 8.3 Illapel, Chile, earthquake: direction-reversed along-dip rupture with localized water reverberation, Bull. seism. Soc. Am., 107, 2416-2426.

Ando, M., 1975. Source mechanisms and tectonic significance of historical earthquakes along the Nankai Trough, Japan, Tectonophysics, 27, 119140.

Beck, S., Barrientos, S., Kausel, E. \& Reyes, M., 1998. Source characteristics of historic earthquakes along the central Chile subduction zone, J. South Am. Earth Sci., 11, 115-129.

Böðvarsson, R. \& Lund, B., 2003. The SIL seismological data acquisition system - as operated in Iceland and in Sweden,in Methods and Applications of Signal Processing in Seismic Network Operations, Vol. 98, pp. 131-148, eds Takanami, T. \& Kitagawa, G., Lecture Notes in Earth Sciences, Springer.

Byerly, P., 1926. The Montana earthquake of June 28, 1925, GMCT, Bull. seism. Soc. Am., 16, 209-265.

Byerly, P., 1928. The nature of the first motion in the Chilean earthquake of November 11, 1922, Am. J. Sci., 232-236.

Byerly, P., 1960. Earthquake mechanisms, Science, 131, 1493-1496.

Cadek, O., 1987. Studying earthquake ground motion in Prague from Wiechert seismograph records, Gerl. Beitr. Geoph, 96, 438-447.

Carlo, D.L., Lay, T., Ammon, C.J. \& Zhang, J., 1999. Rupture process of the 1995 Antofagasta subduction earthquake $(\mathrm{M} \mathrm{w}=8.1)$, in Seismogenic and Tsunamigenic Processes in Shallow Subduction Zones, pp. 677-708, Springer.

Carvajal, M., Cisternas, M., Gubler, A., Catalan, P., Winckler, P. \& Wesson, R.L., 2017a. Reexamination of the magnitudes for the 1906 and 1922 Chilean earthquakes using Japanese tsunami amplitudes: Implications for source depth constraints, J. geophys. Res.: Solid Earth, 122, 4-17.

Carvajal, M., Cisternas, M. \& Catalán, P. A., 2017b. Source of the 1730 Chilean earthquake from historical records: Implications for the future tsunami hazard on the coast of Metropolitan Chile, J. geophys. Res.: Solid Earth, 122, 3648-3660.

Charlier, C. \& Van Gils, J.M., 1953. Liste des stations seismologiques mondiales, bservatoire royal de Belgique, Service séismologique.

Comte, D., Haessler, H., Dorbath, L, Pardo, M., Monfret, T., Lavenu, A., Pontoise, B. \& Hello, Y., 2002. Seismicity and stress distribution in the Copiapo, northern Chile subduction zone using combined on- and offshore seismic observations, Phys. Earth planet. Inter., 132, 197-217.

Davison, C., 1929. The Chilean Earthquake of 1922, Nature, 124, 391-392.

Delouis, B. et al., 1997. The $M_{\mathrm{w}}=8.0$ Antofagasta (northern Chile) earthquake of 30 July 1995: a precursor to the end of the large 1877 gap, Bull. seism. Soc. Am., 87, 427-445.

Duputel, Z., Tsai, V.C., Rivera, L. \& Kanamori, H., 2013. Using centroid time-delays to characterize source durations and identify earthquakes with unique characteristics, Earth planet. Sci. Lett., 374, 92-100.

Geller, R.J. \& Kanamori, H., 1977. Magnitudes of great shallow earthquakes from 1904 to 1952, Bull. seism. Soc. Am., 67, 587-598.

Goodstein, J.R., Kanamori, H. \& Lee, W.H.K., 1980. Seismology microfiche publications from the Caltech archives, Bull. seism. Soc. Am., 70, 657658.

Gutenberg, B., 1914. Ueber Erdbebenwellen. VII A. Beobachtungen an Registrierungen von Fernbeben in Göttingen und Folgerung über die Konstitution des Erdkörpers (mit Tafel), Nachrichten von der Gesellschaft der Wissenschaften zu Göttingen, Mathematisch-Physikalische Klasse, 1914, 125-176.

Gutenberg, B., 1923. 57 Die Bestimmung der Konstanten von Seismometern, in Geologische, Physikalische und Angewandte Erdbebenkunde, eds Sieberg, A. \& Gutenberg, B., Fischer.
Gutenberg, B., 1924. Die Bearbeitung der instrumentellen Aufzeichnungen, Teil II in Sieberg, A. \& Gutenberg, B., 1924. Das Erdbeben in der Chilenischen Provinz Atacama am 10. November, 1922, Veroffentlichungen der Reichsanstalt fur Erdbebenforschung in Jena, 137.

Gutenberg, B., 1939. Tsunamis and earthquakes, Bull. seism. Soc. Am., 29, $517-526$.

Gutenberg, B. \& Richter, C.F., 1954. Seismicity of the Earth and Associated Phenomena, 2nd edn, p. 310, Princeton Univ. Press.

Heidarzadeh, M., Murotani, S., Satake, K., Ishibe, T. \& Gusman, A.R., 2016. Source model of the 16 September 2015 Illapel, Chile, $M_{\mathrm{W}} 8.4$ earthquake based on teleseismic and tsunami data, Geophys. Res. Lett., 43, 643-650.

Ihmlé, P.F. \& Madariaga, R., 1996. Monochromatic body waves excited by great subduction zone earthquakes, Geophys. Res. Lett., 23, 2999-3002.

Imamura, A., 1928. On the seismic activity of central Japan, Jpn. J. Astron. Geophys., 6, 119.

Imamura, A., 1937. Theoretical and Applied Seismology, 358pp. Maruzen Company, doi:10.11501/1677328.

International Latitude Observatory of Mizusawa, 1984. Seismological Observations at Mizusawa, pp. 1-379, The International Latitude Observatory of Mizusawa, Mizusawa, Japan.

Kanamori, H., 1977. The energy release in great earthquakes, J. geophys. Res., 82, 2981-2987.

Kanamori, H. \& McNally, K.C., 1982. Variable rupture mode of the subduction zone along the Ecuador-Colombia coast, Bull. seism. Soc. Am., $\mathbf{7 2 ,}$ $1241-1253$.

Kanamori, H., Rivera, L. \& Lee, W.H., 2010. Historical seismograms for unravelling a mysterious earthquake: the 1907 Sumatra earthquake, Geophys. J. Int., 183, 358-374.

Kawasumi, H., 1937. An historical sketch of the development of knowledge concerning the initial motion of an earthquake. Publ. du Bureau Central Séismologique International. Ser. A, Travaux Scientifiques. Fasc. 15, 2nd part, pp. 258-330.

Kelleher, J.A., 1972. Rupture zones of large South American earthquakes and some predictions, J. geophys. Res., 77, 2087-2103.

Kulhanek, O. \& Wahlstrøm, R., 1996. History of Instrumental seismological observations in Sweden, in Seismolograph Recording in Sweden, Norwaywith Arctic Regions, Denmark-with Greenland and Finland. Proc. The Uppsala Wiechert Jubilee Seminar, ed. Wahlstrum, R. Uppsala.

Li, L., Lay, T., Cheung, K.F. \& Ye, L., 2016. Joint modeling of teleseismic and tsunami wave observations to constrain the 16 September 2015 Illapel, Chile, $M_{\mathrm{w}} 8.3$ earthquake rupture process, Geophys. Res. Lett., 43, 43034312.

Lienkaemper, J., 1984. Comparison of two surface-wave magnitude scales: M of Gutenberg and Richter (1954) and Ms of "Preliminary Determination of Epicenters", Bull. seism. Soc. Am., 74, 2357-2378.

Liu, C., An, C., Shan, B., Xiong, X. \& Chen, X., 2018. Insights into the kinematic rupture of the $2015 M_{\mathrm{W}} 8.3$ Illapel, Chile, earthquake from joint analysis of geodetic, seismological, tsunami, and superconductive gravimeter observations, J. Geophys. Res.: Solid Earth, 123, 9778-9799.

Lomnitz, C., 1970. Major earthquakes and tsunamis in Chile during the period 1535 to 1955 , Geol. Rundsch., 59, 938-960.

Lomnitz, C., 2004. Major earthquakes of Chile: a historical survey, 1535 1960, Seismol. Res. Lett., 75, 368-378.

Matuzawa, T., 1929. Observation of some recent earthquakes and their timedistance curves (part IV), Bull. Earthq. Res. Inst., Univ. Tokyo, 6, 218-229.

Melgar, D. et al., 2016. Slip segmentation and slow rupture to the trench during the 2015, $M_{\mathrm{w}} 8$. 3 Illapel, Chile earthquake, Geophys. Res. Lett., 43, 961-966.

Métois, M., Vigny, C. \& Socquet, A., 2016. Interseismic coupling, megathrust earthquakes and seismic swarms along the Chilean subduction zone $\left(38^{\circ}-18^{\circ}\right.$ S), Pure appl. Geophys., 173, 1431-1449.

Nishenko, S.P., 1985. Seismic potential for large and great interplate earthquakes along the Chilean and southern Peruvian margins of South America: a quantitative reappraisal, J. geophys. Res., 90, 2589-3615.

Okal, E.A., 1992. Use of the mantle magnitude Mm for the reassessment of the moment of historical earthquakes I: shallow events, Pure appl. Geophys., 139, 17-57. 
Okamoto, T., 1993. Effects of sedimentary structure and bathymetry near the source on teleseismic P waveforms from shallow subduction zone earthquakes, Geophys. J. Int., 112, 471-480.

Oldham, R.D., 1906. The constitution of the interior of the Earth, as revealed by earthquakes, Quart. J. Geol. Soc., 62, 456-475.

Press, F., 1959. Some implications on mantle and crustal structure from $\mathrm{G}$ waves and Love waves, J. geophys. Res., 64, 565-568.

Pritchard, M., Simons, M., Rosen, P., Hensley, S. \& Webb, F., 2002. Coseismic slip from the 1995 July $30 \mathrm{Mw}=8.1$ Antofagasta, Chile, earthquake as constrained by InSAR and GPS observations, Geophys. J. Int., 150, 362-376.

Richter, C.F., 1958. Elementaty Seismology, pp. 768, W. H. Freeman and Cooper.

Ruegg, J. et al., 1996. The $M_{\mathrm{w}}=8.1$ Antofagasta (North Chile) earthquake of July 30, 1995: first results from teleseismic and geodetic data, Geophys. Res. Lett., 23, 917-920.

Ruiz, S. \& Madariaga, R., 2018. Historical and recent large megathrust earthquakes in Chile, Tectonophysics, 733, 37-56.

Satô, Y., 1958. Attenuation, dispersion, and the wave guide of the $\mathrm{G}$ wave, Bull. seism. Soc. Am., 48, 231-251.

Satô, Y., 1978. Theory of Elastic Waves (translated from Japanes, Dansei Hadou Ron, pp. 1-454, Iwanami Publisher.

Shida, T., 1929. Review of the study of rigidity of the Earth and the initial motion of seismic waves, Toyo Gakuyei Zasshi [East Asian J. Sci.], 45, 275-289.

Sieberg, A. \& Gutenberg, B., 1924. Das Erdbeben in der Chilenischen Provinz Atacama am 10. November, 1922, Veroffentlichungen der Reichsanstalt fur Erdbebenforschung in Jena, 137.

Soloviev, S.L. \& Go, Ch.N., 1975. A catalogue of tsunamis on the eastern shore of the Pacific Ocean (1513-1968). Nauka Publishing House, Moscow, USSR, 204 pp. Can. Transl. Fish Aquat. Sci. 5078, 294 pp.

Storchak, D., Di Giacomo, D., Engdahl, E., Harris, J., Bondár, I., Lee, W., Bormann, P. \& Villaseñor, A., 2015. The ISC-GEM global instrumental earthquake catalogue (1900-2009): introduction, Phys. Earth planet. Inter., 239, 48-63.

Tilmann, F. et al., 2016. The 2015 Illapel earthquake, central Chile: a type case for a characteristic earthquake? Geophys. Res. Lett., 43, 574-583.

Vanek, J., Zatopek, A., Karnik, V., Kondorskaya, N., Riznichenko, Y.V., Savarensky, E., Solov'ev, S. \& Shebalin, N., 1962. Standardization of magnitude scales, Izv. Acad. Sci. G. Ser. USSR, 2, 108-111.

Wiens, D.A., 1989. Bathymetric effects on body waveforms from shallow subduction zone earthquakes and application to seismic processes in the Kurile trench, J. geophys. Res.: Solid Earth, 94, 2955-2972.

Willis, B., 1929. Studies in Comparative Seismology: Earthquake Conditions in Chile, Vol. 382, 178pp., Carnegie Institution of Washington.

Ye, L., Lay, T., Kanamori, H. \& Rivera, L., 2016. Rupture characteristics of major and great $\left(M_{\mathrm{w}} \geq 7.0\right)$ megathrust earthquakes from 1990 to 2015: 1. Source parameter scaling relationships, J. geophys. Res.: Solid Earth, 121, 826-844.

Ye, L., Lay, T., Kanamori, H. \& Koper, K.D., 2017. Rapidly estimated seismic source parameters for the 16 September 2015 Illapel, Chile M w 8.3 earthquake, in The Chile-2015 (Illapel) Earthquake and Tsunami, pp. 11-22, Springer.

\section{APPENDIX:CALIBRATION OF THE HONGO OMORI SEISMOGRAPH}

The calibration data of the Hongo Omori seismograph that we used are briefly given in 'Miscellaneous Notes', now archived at the National Museum of Nature and Science, Tsukuba, Japan. The date given to this material is May, 1920 but it includes the information before and after this date. This document has more than 100 pages of hand-written notes mainly in Japanese; some may be by Professor Fusakichi Omori.

Following is the summary for the period prior to November 1923.

Period 1903.3.2-1917.6.13

EW component $V=15, T_{s}=61-63.7 \mathrm{~s}$

NS component $V=20, T_{s}=29.93-60.0 \mathrm{~s}$

Period 1917.6.13-1922.10.6 no reports

1922.10.6

EW component $V=10$

NS component $V=20$

Period 1922.10.6-1923.11.19 (after the 1923 Kanto earthquake) no reports

Thus, unfortunately, the response at the time of the 1922 event was not well documented.

On the NS component record of the date of the 1922 event, we can see a waveform which looks like a calibration pulse, shown in Fig. A1. Although no details could be found, the waveform looks like the one for Wiechert seismogram shown by Gutenberg (1923) and in the Observatory Manual of the Central Meteorological Agency published in 1936. The calibration pulse of the Wiechert seismograph (Fig. A2) is the response of the seismograph when a small mass $p$ (left-hand panel, Fig. A2) is placed off-centre on the seismograph weight, and is removed a few minutes later. Thus, the transient response in the beginning and at the end correspond to the response to a step function in force with the polarity reversed.

Comparison of Figs A1 and A2 suggests that Fig. A1 shows the response of the Omori seismograph to a step function in force. However, we can see several problems: (1) The transient response in the beginning and at the end are different. (2) the damping seems to be stronger at the end. Since the signal in the beginning seems to be overdriven and non-linear, we investigate the transient signal at the end (in the blue box).

The response of a mechanical seismograph with a pendulum period $T_{s}$ and damping constant $h$ to a step function in force is proportional to

$$
\begin{array}{r}
r(t)=1-\exp \left(-h \omega_{s} t\right)\left[\frac{h}{\sqrt{1-h^{2}}} \sin \left(\sqrt{1-h^{2}} \omega_{s} t\right)\right. \\
\left.+\cos \left(\sqrt{1-h^{2}} \omega_{s} t\right)\right],
\end{array}
$$

where $\omega_{s}=\frac{2 \pi}{T_{s}}$.

Fig. A3 shows the response functions for $T_{s}=40,50$ and $60 \mathrm{~s}$, and $h=0.3,0.4,0.5$ and 0.6. Although none of them matches the observed response shown in Fig. A1 completely, it is evident that $h=0.3$ and 0.4 are inadequate because they give too many oscillations. Also, the $T_{s}=60 \mathrm{~s}$ case yields too long-period oscillations. The real response can be approximated by a combination of $T_{s}=50 \mathrm{~s}$, and $40 \mathrm{~s}$ and $h=0.5$ and 0.6 . Thus, given all the uncertainties resulting from the calibration method and the possible solid friction, we consider that the choice we made in section $3\left(T_{s}=40 \mathrm{~s}\right.$ and $h=0.6$ ) with a completely different method is satisfactory. Unfortunately, since the magnitude of the force used for calibration is unknown, we cannot estimate the static magnification. 


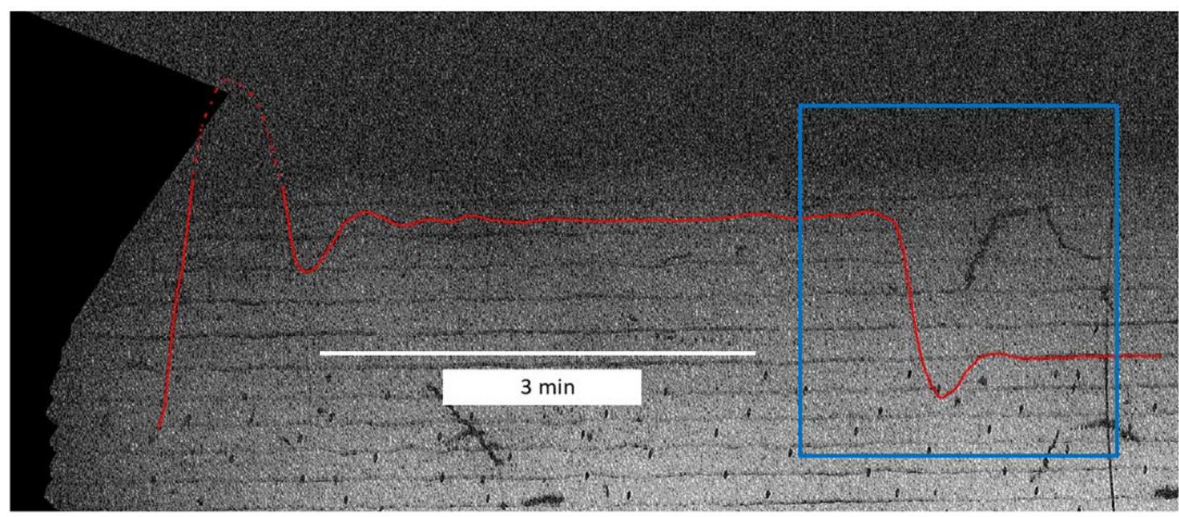

Figure A1. Calibration pulse on the NS component of the Omori seismogram of 11 November 1922 at Hongo.

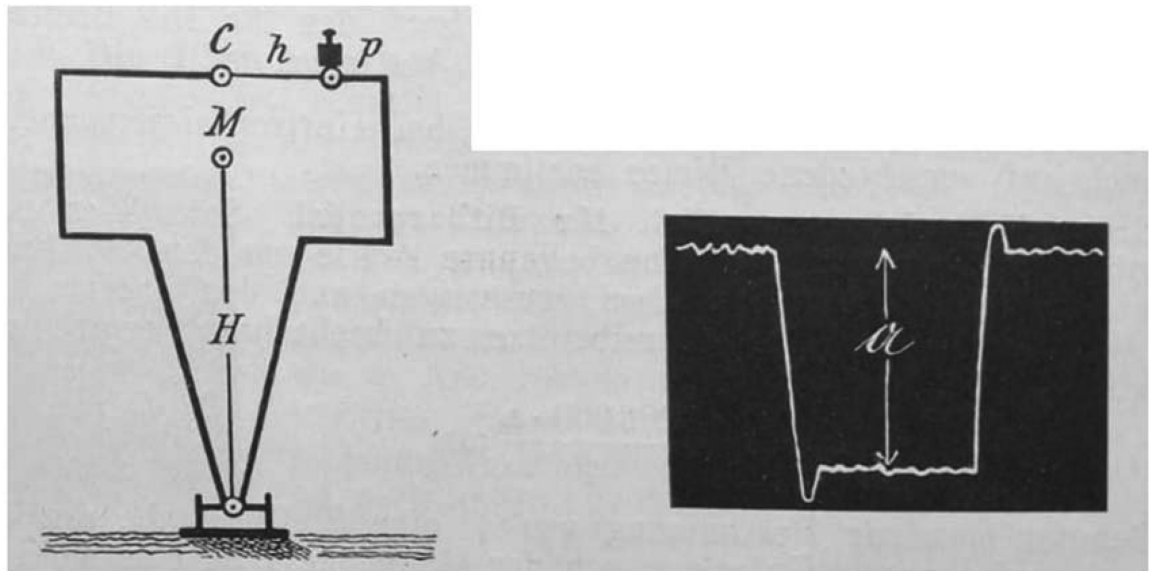

Figure A2. Schematic figure illustrating the calibration of a Wiechert seismograph (left-hand panel) and the calibration pulse (right-hand panel), (Gutenberg 1923).
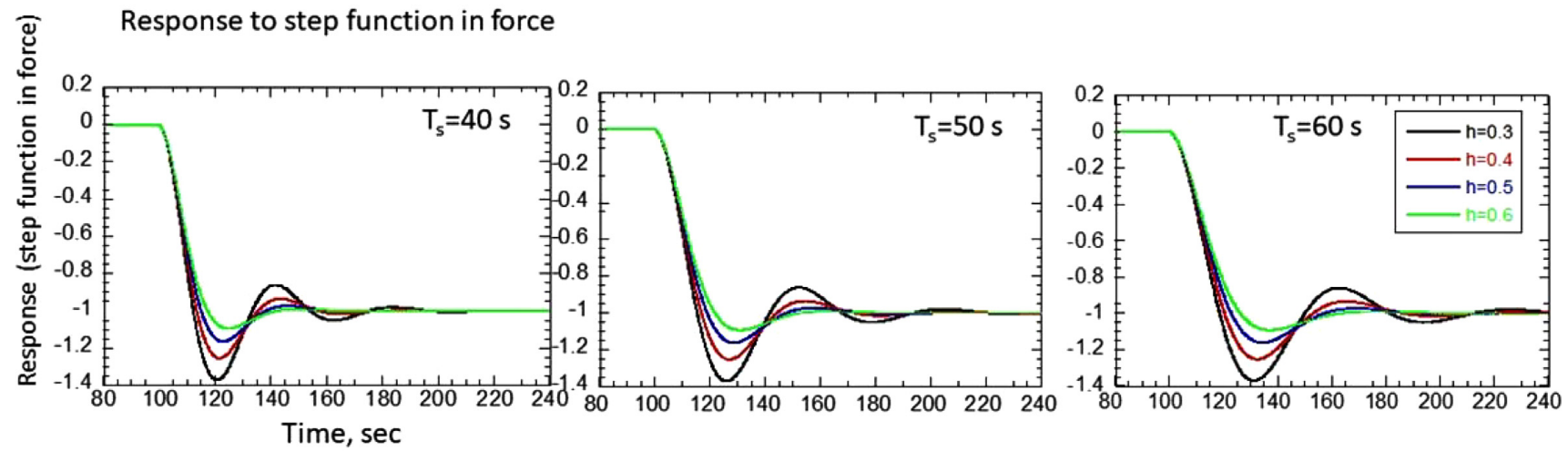

Figure A3. Response (to a step function in force) of mechanical seismographs for various $T_{s}$ (pendulum period) and $h$ (damping constant). 